\title{
Cames
}

and

Exercises for

Mental

Defectives

UC-NRLF

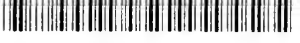

5B I? B 10 


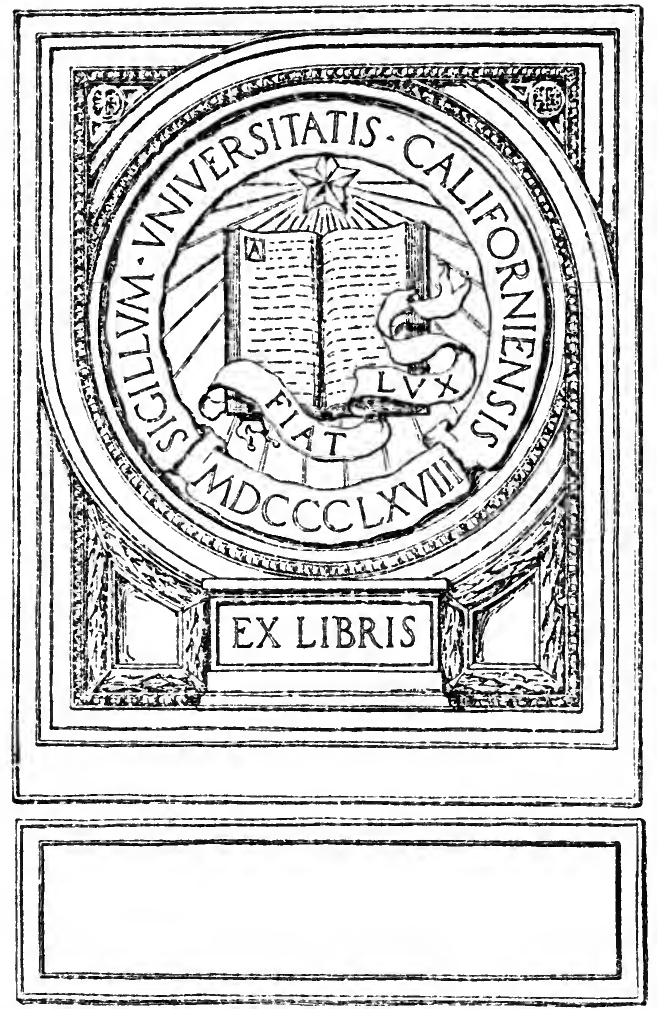


Digitized by the Internet Archive in 2007 with funding from Microsoft Corporation 


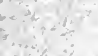




\section{GAMES AND EXERCISES FOR MENTAL DEFECTIVES}





\title{
GAMES AND EXERCISES FOR
}

\section{MENTAL DEFECTIVES}

\author{
BY \\ HILDA A. WRIGHTSON
}

"The one idea no sooner comes into the understanding than its associate appears with it."-Locke.

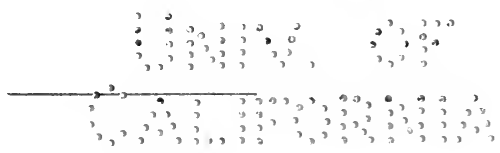

CAMBRIDGE, MASS.

CAUSTIC.CLAFLIN CO., PUBLISHERS, HARVARD SQUARE 
$L^{4^{6}}$
$w^{8}$

Copyright, 19I6,

By Hilda A. Wrightson

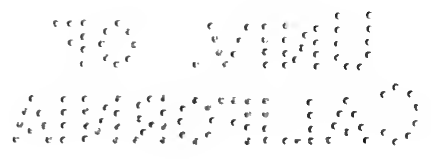




\section{PREFACE}

7 HE training possible with feeble-minded children ranges from that which will enable them "to eat a little less like an animal and make known their physical wants"-in the case of idiots-up to considerable efficiency in certain lines of manual and industrial work, for the morons. Reading, Writing and Arithmetic as formal studies are of but little value-only a small percentage of the very highest grades ever attaining enough efficiency to make use of them after instruction ceases.

Defectives of all grades lack energy and initiative. They do not therefore, of their own accord, develop the physical coördinations that normal children do. Accordingly they must be exercised along these lines if they are to attain to the highest of their limited capacity.

Not having the judgment and foresight, the ambition, of normal children, special efforts must be put forward to hold their interest while exercises for coördination are being given.

The most natural way to accomplish this is through the medium of games.

Miss Wrightson has brought together in convenient form a large number of games especially adapted to accomplish 
these results. Her long experience with feeble-minded children is a guarantee of their usefulness and efficacy for the purpose.

It should be fully appreciated by teachers, parents and superintendents that the playing of these games is not "mere play," but definite training of the best kind. In many cases there is little else to be done.

The teacher should select such games as are most interesting to her special group and practice these until the children are reasonably proficient in them or until they prove uninteresting.

The teacher unfamiliar with feeble minds will perhaps think some of the games here described of no value. It is always hard for the more intelligent to understand the less intelligent, for normal teachers to understand defective children. It should be remembered that the joy of accomplishment is one of the greatest joys of life for all grades of intelligence. It is the fact that the list includes games adapted to the simplest minds which constitutes one of its excellencies.

It should not be forgotten that these games not only develop coördination and attention; manners, morals, self-control, altruism, patience and many more desirable qualities are involved. What more can education do than develop 
to the limit of the individual's capacity these qualities which, possessed even in a small degree, will help to make him a social rather than an anti-social being!

\section{HENRY H. GoDdARD.}

Vineland, N. J.

December, 1915 . 
$+2$

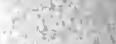

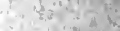

ing $42 . y$ in

in $\quad i^{2}$

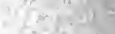

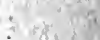

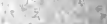

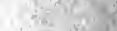

i.menting

$y^{2}+2 y$ ic $x^{2}+x^{2}$
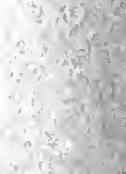


\section{PRACTICAL HINTS FOR TRAINING MENTAL DEFECTIVES}

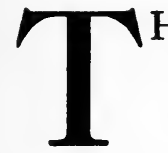

$\mathrm{HE}$ games and exercises in this book were written for use among mothers and teachers of feebleminded children, the object being to help develop muscular control and to quicken the sense perceptions. The most difficult among the exercises could be mastered with ease by a normal child six years of age. The following instructions should be observed:

I. Each one of the exercises should be put before the child in a spirit of play, thereby doing away in some measure with depression and inertia.

2. Absolute simplicity in the training is essential. The manner in which a game is played is of more importance than the game itself. A simple game or exercise taught in a complex manner will produce a confusion of ideas in the mind of the child and mean failure in training.

3. Aim to produce one idea at a time in the mind of the child.

4. In teaching mental defectives the personality of the teacher plays an important part. She should be patient, cheerful and optimistic, always ready with a word of encouragement when a child fails to produce desired results; thorough in her methods and of keen perception. The mind of the teacher reacts upon the mind of the child: "Education is one mind making another mind and one heart another heart."

5. It will be found in many cases that the principal weakness in these children is their lack of concentrative- 
ness, and it is only by simple, fixed methods of work, elimination of all confusion, and the conviction of the teacher that good results must emanate from her training that she can develop and strengthen this latent power in the child. One game or exercise thoroughly and systematically taught will prove of more lasting value in training the child, than one dozen taught in a manner void of method. The mode of procedure must not vary; children should be lined up in the same way, material of the same color must be used, and diagrams drawn precisely the same way each time the game or exercise is used. Should the smallest alteration be made in these details, it will produce a confusion of ideas in the child's mind and successful training will not result.

6. The given signal for starting a game should be brief, as, "Are you ready?" followed by the word "Go!" said sharply and clearly. A signal with too many words is confusing. Always use the same form of signal in starting a game. Should this be changed ever so little the game will not start successfully, for the child's mind will be centered upon that change and he will lose the all-important idea, $e . g$., the start of the game. A game unsuccessfully started is a failure throughout.

7. Competitive games should always be played single file at first until children become acquainted with the game.

8. Mental defectives cannot be allowed the free play accorded normal children; to get good results their play must be supervised at all times. The play spirit is undeveloped in most of these children and our object is to endeavor to stimulate its growth until the child plays, not because it has to, but because it wants to.

9. Make all exercises as attractive as possible; aim to have an air of peace and tranquillity in the school- 
room. Tension in the slightest degree is disastrous to the training. The schoolroom should be made a pleasure-ground for the child. Bear in mind the best discipline always attends the most successful play.

ro. It is not advisable to keep a child for longer than one hour at a session. In a longer session it will be noticed the child becomes depressed or restless and power of concentration becomes weaker. During the session a child should not be kept too long at one exercise; from four to ten minutes is sufficient for any of the exercises. Should a child be kept twenty minutes at one exercise, more will be gained during the first five minutes than the latter fifteen minutes. A game played too many times in an effort to perfect it, loses its object.

I I. Two inactive exercises should not follow each other consecutively.

I 2. In teaching rhymes and songs, introduce simple action. It will help to develop sense of rhythm and be found to aid the memory in a marked degree.

13. In drawing diagrams on a polished wood floor, better results can be obtained by moistening the chalk.

The materials used in these exercises and games should be very simple. Bean bags should be made five inches square, of bright-colored cloth of heavy texture, and filled with small, hard beans. The wooden blocks should be eight inches in length, and one and a half inches on each side; the corners should be sharp so that they may be stood on end without difficulty. Gas balls, medicine balls, and baseballs should be regulation size.

Hilda A. Wrightson. 

PART I. 

1.

\section{BEAN BAG CATCH}

Material.-Ten bright colored bean bags.

Children sit in semi-circle on small chairs.

Teacher stands in front of class and throws bean bags, endeavoring to put one into the hands of each child as they sit in class.

It is well to throw the bags first to a child on one side of the class, then to a child on the other side; the children will become more alert when the bag is thrown unexpectedly. When all bean bags have been thrown, tell children to throw them back to teacher.

Choose two players to pick up fallen bean bags and return them to teacher.

Object.-Train eye and hand for ball-catching; concentration; stimulate play spirit.

\section{ROLL BALL}

Material.-Medicine Ball.

Have children sit in semi-circle on small chairs.

Mark two parallel lines on the floor twelve feet apart and four feet in length.

Teacher stands on one line and rolls the ball slowly in the direction of second line, meanwhile calling upon $\mathrm{A}$ to catch the ball before it can reach second line.

A will leave seat to catch the ball, and roll it back to teacher, who will again roll ball, calling upon B to catch it before reaching second line.

As children become more alert, the ball may be rolled more quickly. Those children who can talk may be allowed to roll the ball and call a child's name.

Object.-Attention; spirit of play; muscular control. 
3.

\section{BEAN BAG TOSS}

Material.-Shallow box, bean bags.

Children sit in a circle on the floor, three feet apart.

Place a large, shallow box in the centre of circle. Give each child a bean bag.

Have the children each throw their bean bag, in turn, endeavoring to get it into the box in centre of circle.

Note.-This game is especially adapted for crippled children and those unable to take part in active games.

\section{COLOR}

Material.-Equal number of red, blue, and yellow blocks.

Children sit in semi-circle. Give each child one block.

Make three chalk circles in row on floor in front of class; place red block in one, blue block in one, and yellow block in the other.

Call upon children to come from their seats in turn and place their blocks in circles calling for like colors.

Do not let second child play until first child has returned to her seat, thereby avoiding confusion. Do not attempt to call the colors by name; children will match them more successfully by sense of sight alone.

Variation.-Four circles may be used, and green introduced when above colors are mastered.

Object.-Develop color sense and concentration. 


\section{COMMAND AND CONCENTRATION}

Material.-Soap, spoon, cup, doll, ball, comb, toothbrush, or any article the child is apt to come in contact with in daily life.

The teacher should place these articles in a row on the table, and then tell one of the children to give her the toothbrush. Say the words slowly and distinctly that the child may understand exactly what is wanted. When the child has handed the toothbrush to the teacher, ask for each article in turn. If the child is unable to concentrate for sufficient length of time to pick up the desired article, do not try to force its attention; send the child to its seat with a word of encouragement, and try the exercise each succeeding day until slowly but surely the child's attention will become strong enough to master the exercise.

6.

\section{BOWLING}

Material.-Two dozen bright colored blocks. Six colored baseballs. Colors-blue, yellow, red, and green.

Draw a chalk circle three feet in diameter; make a start. ing line fifteen feet from circle.

Place blocks on end inside circle, not too closely together. Call upon child to stand on starting line and bowl balls one at a time, endeavoring to knock down as many blocks as possible.

Variation.-Two circles may be drawn and two starting lines.

Two players may bowl at the same time; the child having knocked down the greater number of blocks wins.

Choose two children to stand up the fallen blocks; also two or more children to fetch scattered balls.

Object.-To develop sureness of aim; attention; muscular control. 


\section{MEMORY AND COMMAND}

Teacher calls the names of three children to stand on chalk line made for that purpose in front of class. Call names distinctly, but do not make a pause between each name. The children whose names are called will leave their seats and stand side by side on chalk line.

If it is found three names are too confusing for the children to remember, teacher should use only two to start the exercise.

When children have become accustomed to remembering their names when three are called, teacher slowly increases the number, always bearing in mind it is better to have the exercise too simple rather than too complicated for the child.

8.

\section{BALL THROW}

Material.-Medicine ball.

Have children stand in group at one end of the room.

Teacher throws medicine ball into their midst; child catching the ball throws it back to teacher, who will immediately repeat the exercise. Encourage children to run after the ball when it falls to the ground. Do not call upon any particular child to catch the ball; by throwing it in their midst and letting those catch it who can, the children will become more alert.

Should a child be very slow, it is well to call upon that child in particular to catch.

Object.-Train eye and hand for ball catching; develop play spirit. 
9.

\section{SILENCE PERIOD}

It is very important that a period of silence be maintained from three to five minutes during one hour classes.

Have the children sit with arms folded and knees close together, each child erect in his seat. As far as it is possible have perfect quiet in the class room, let no one make a sound.

Teachers will find after a period of silence children will concentrate more readily, and their restlessness will have abated materially.

Object.-Rest; attention; concentration.

10. BLOCK PLACING

Material.-Wooden blocks of one color, according to number of children playing.

Make a line of small chalk crosses on the floor twelve inches between each cross; draw a starting line parallel with crosses, eighteen feet between.

Give each child a block and have them stand in position on starting line.

At a given signal have children run and place their blocks on one of the crosses, then back to starting line.

The blocks must be placed on end upon the crosses; should a block fall, the child must place it upright again.

This exercise may be repeated three or four times.

Object.-To develop muscular control; attention; and to stimulate the spirit of play in the child. 


\section{$11 . \quad$ COLOR EXERCISE}

Material.-Six bright colored balls-two red, two blue, two yellow.

Place three balls on the table, one of each color, teacher holding the duplicates.

Hold up red ball that all may see it, and call upon A to pick out ball of same color on the table. When A has picked out red ball, teacher should hold up blue ball, and call upon B to find duplicate. Do not call the balls by color name. The child will develop color sense more quickly if name of color is omitted at this stage.

Object.-Develop color sense and attention.

\section{ROLLING ROUNDERS}

Material.-Medicine ball.

Children sit in a circle, five feet between each player.

The ball must be rolled from one player to the next, all the way round the circle; it is well to choose one player to run after the ball when it rolls away from the circle.

For variety the ball may also be rolled across the circle.

This game is especially beneficial for crippled children, and those unable to take part in active games.

Object.-Muscular control; attention; play spirit. 


\section{MUSCULAR CONTROL}

Have all children stand three feet apart.

Raise arms to the level of shoulders, palms towards the floor. On command, children should raise heels from the floor and slowly lower them again.

Arms must be kept perfectly straight while this exercise is being performed.

Repeat the exercise six times, then the arms may be lowered, and a short space of time allowed for rest.

Object.-Concentration and muscular control.

\section{SHOE-LACING EXERCISE}

Draw a chalk line on floor and have children stand with both feet on line.

At command, children should sit on floor and take off one shoe.

Among the more defective children it is well for the teacher to unfasten the bow on each child's shoe before the exercise begins, or the children will be apt to pull their laces into innumerable knots, thereby causing much confusion.

When each child has removed one shoe, teacher may tell them all to put shoes on again, and see who can lace his first.

Object.-Attention; ability to dress themselves. 


\section{BEAN BAG THROW}

Material.-Three bean bags, red, blue, and yellow in color.

Teacher should draw a chalk circle on floor about three feet in diameter, and make a starting line twelve feet from circle.

Have child stand on starting line and throw each bean bag, endeavoring to get them into the chalk circle.

This game may be varied by having two circles and letting two children play at the same time; in such cases it is well to have red bean bags used in one circle and blue bean bags in the other.

Object.-Train eye and hand for throwing games.

16. HEARING EXERCISE

Material.-Clear-sounding bell.

Call upon two children to perform.

Have A stand at one end of the room and ring a bell.

Blindfold $B$ and take her to the opposite side of the room and let her find her way to A guided by her sense of hearing.

A must not move and must keep the bell ringing constantly.

This exercise is beneficial for mental defectives in the first stages of hearing development.

Object.-Concentration; hearing. 


\section{MEDICINE BALL THROW}

Material.-Medicine ball.

Children stand in semi-circle.

Teacher should throw ball to child in centre of class, the child then throws the ball back to teacher. The ball is again thrown by teacher to another child in class, the game continuing in this way, teacher throwing the ball and children returning it.

Do not play in rotation; the children's attention will be held better if ball is thrown unexpectedly to different parts of the class.

Object.-Train eyes and hands for ball catching; attention; develop play spirit.

18. TIPTOE EXERCISE

Have the children sit perfectly quiet; let no noise be heard in the room; maintain quiet in the room for two or three minutes before starting exercise.

Teacher calls upon A to perform; he should stand up with arms folded and walk on tiptoe around teacher's chair (or to a given point) and back to his seat.

Teacher continues the exercise, encouraging each child to do just a little better than the preceding child.

Care should be taken not to continue this exercise too long. Four minutes is sufficient.

Object.-Rest; concentration; discipline. 


\section{9.}

PULLING EXERCISE

Material.-A strong rope about twelve feet in length.

Choose six players as evenly matched in size and height as possible.

Make two starting lines four feet apart on which the leader of each side will stand.

At a given signal the three players on one side should pull in an opposite direction to the three players on the other side.

It will be found when this exercise is started some of the children will be apt to let go of the rope when they feel others pulling, and some will pull aimlessly, neither giving help to one side or the other. Do not try to force the child to pull the rope in the right way. Continual use of this exercise and observation will bring about desired results.

This exercise is a slight variation of tug-o'-war.

Object.-Develop muscular control ; concentration; command.

\section{COMMAND AND CONCENTRATION}

Material.-Red ball, blue bean bag.

Place the above articles on table and call upon child to perform.

Teacher may give commands in the following order, speaking slowly and distinctly:

Pick up ball and hold it.

Pick up bean bag and hold it.

Put down ball.

Put down bean bag.

Pick up ball and hold it.

Put down ball and pick up bean bag and hold it.

Put down bean bag.

Teacher should pause between each action, that the child may not become confused. 


\section{BELL CIRCLE}

Material.-Six bright colored baseballs; one bell.

Have children sit in a circle on the floor, a small space between each child. Use the most active child for running after balls that go astray.

Place the bell in the middle of the circle and give six of the children each a baseball.

The children should play in order, each one rolling his ball and endeavoring to hit the bell and make it ring.

This game is very good for crippled children, and those unable to take part in running games.

Object.-Develop play spirit; attention.

22.

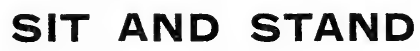

The class should be seated in a half-circle on kindergarten chairs.

Children should sit erect, arms folded, feet together.

At a signal given by the teacher all children stand; there must be no scuffling of feet or confusion of any kind; arms must not be moved; and all stand quickly on the given signal. Signal will then be given for all children to sit; this must also be done with precision.

This exercise may be repeated four or five times in succession.

Note.-To vary this exercise children may clasp their hands tightly behind their backs, each hand grasping an elbow. The exercise will be found more difficult to perform with arms folded in this manner.

Object.-Muscular control; attention; discipline. 


\section{3.}

\section{SENSE OF DIRECTION}

Place four chairs in a straight row; call upon four children to come and sit in these chairs; tell each child to notice the chair in which she is sitting and the child next to whom she is sitting.

On signal have children all get up from chairs and walk the whole way around the room. When they reach their chairs again, each child must sit in precisely the same chair she had when exercise began.

As children advance in this exercise the number of chairs may be increased, always taking care lest the exercise become too complex.

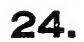

\section{HOOP GAME}

Material.-A wooden hoop four feet in diameter, covered with bright blue or red binding; bean bags.

Have two of the larger pupils hold hoop three feet from ground, children meanwhile standing in a group on one side of hoop, teacher standing on opposite side.

Teacher then takes six bright colored bean bags and throws them one at a time through the hoop into the hands of the children on the opposite side. When children have all the bean bags on their side they should throw them back through hoop to teacher, and game will be repeated.

The teacher's assistant should pick up fallen bean bags and place them in the hands of those children who are not able to catch readily.

The weaker and more deficient children must be paid special attention in these group games and exercises, or they will be pushed to the wall by their stronger companions and derive no benefit whatever.

Object.-Stimulate play spirit; train hand and eye for ball catching; attention. 
PART II. 


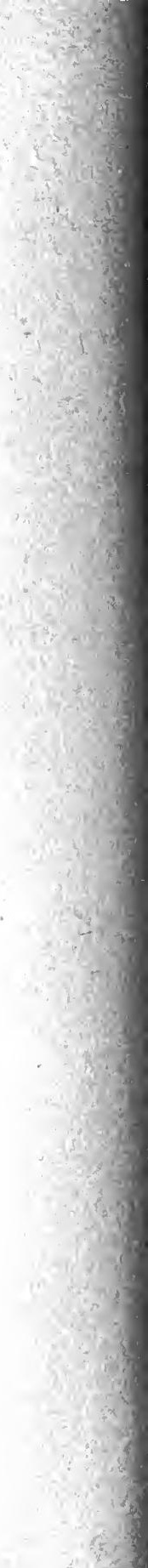




\section{DIRECTION AND COMMAND}

Material.-Cup, spoon, hairbrush, or any article used in everyday life of the child.

Teacher should place above articles in different parts of the room; for instance, put the cup on a chair; the spoon on the table; the hairbrush on another chair. Each article must be in such a position it can be easily seen by the child.

Call upon A to bring the cup to teacher; call upon B to bring the spoon; continue the exercise, calling upon different children to perform until all the articles have been brought to teacher.

26.

\section{VISUALIZATION}

Have class seated in semi-circle.

Place four different articles in a row on the table; these articles must be objects which the child is likely to come in contact with every day, such as soap, cup, spoon, comb. Call upon one child and ask him to look at the articles on the table, then blind his eyes and remove the cup; take bandage from child's eyes and ask him which article was removed from the table.

Should the child be unable to visualize as many as four articles, use only three to start the exercise. When children can readily visualize four, slowly increase number of articles.

Object.-Memory and concentration. 


\section{SINGLE LINE BLOCK STANDING}

Material.-Equal number of red, blue, and yellow blocks.

Line up children in single file according to height. Chalk floor as per diagram. Give each child a block.

The leader will stand on starting line. At a given signal he will run and place his block on end in the circle, after which he will run to rear of line, and second boy will take his turn.

Should a child knock other blocks down while placing his, he must stand them up again before taking his place at rear of line.

Continue until each child has placed its block.

Object.-Attention; muscular control; spirit of play.

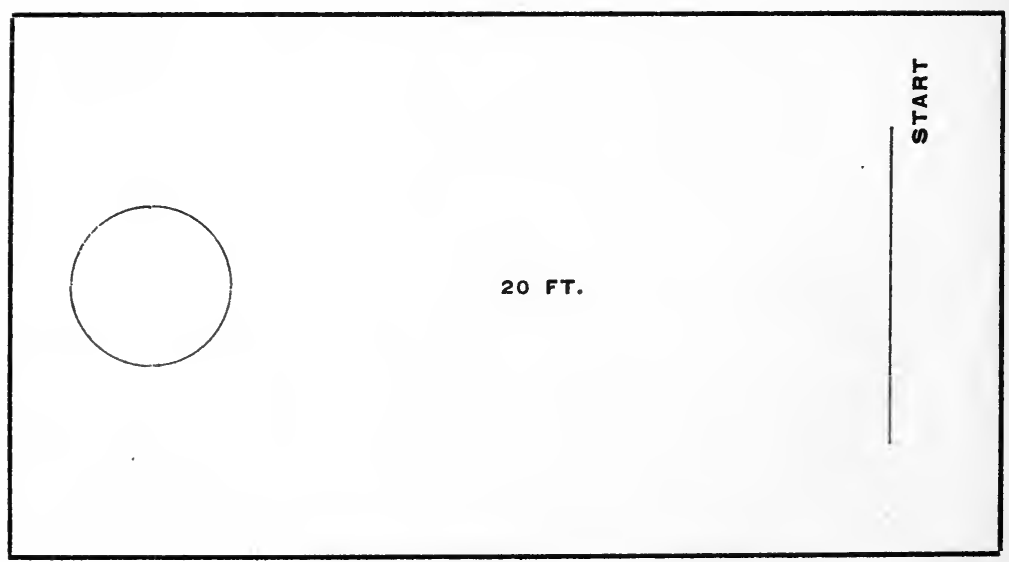




\section{WALKING EXERCISE}

I. Teacher should draw a straight chalk line along the floor. Have child walk line slowly, taking care to place both heel and toe on line at every step.

2. Walk line with hands placed firmly on hips and elbows out.

3. Walk line with hands clasping elbows at back.

4. Walk line with hands clasped in nape of neck; elbows out.

5. Walk line with arms outstretched on level with shoulders, fingers straight, palms down.

6. Have child place feet close together and with hands on hips, take short jumping steps from one end of line to the other.

7. Place hands on hips and hop on one foot; take care to have foot on line at every hopping step.

Object.-To develop muscular control; attention and coordination.

\section{COMMAND AND OBSERVATION}

Teacher should call $A$ and tell him to stand in one corner of the room; call B and tell him to go to another corner; call $\mathrm{C}$ and $\mathrm{D}$ to go to the other two corners; call $\mathrm{E}$ to stand in the middle of the room. When this is accomplished, send the five children to their seats and choose another five to repeat the exercise.

Object.-Observation; memory. 


\section{0.}

\section{BROAD JUMP}

Teacher should draw two parallel lines with eightinch space between. Should this game be played out of doors, sticks will very readily take the place of chalk lines. Line up children in single file according to height, and at a given signal first player runs and jumps over the parallel lines.

Have a starting line fifteen feet distant from jumping space on either side, that the exercise may be more orderly, and players may line up each time they have jumped, and stand still in place until last player has jumped.

Teacher should widen jumping-space about two inches each time, or according to ability of players.

To gain results this exercise must be carried out in a very orderly manner; any confusion among the children will spoil results.

Object.-Muscular control; concentration.

\section{MUSCULAR CONTROL}

Material.-Spoon and ball.

Make two parallel lines on the floor eighteen feet apart.

Take a spoon and put a ball in it.

Have child balance ball in spoon and walk from starting line to the opposite line and back to starting line. No effort at speed is necessary.

This exercise may be varied by making it competitive. Have two children walk at the same time, each carrying a spoon and balancing a ball. The child that gets back to starting line first wins the race.

Object.-Muscular control; concentration. 


\section{BEAN BAG THROW}
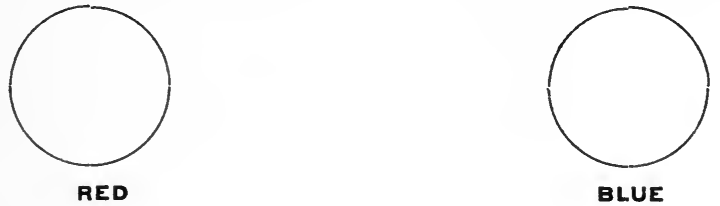

BLUE

$\stackrel{\circ}{\circ}$

START

START

Material.-Equal number of red and blue bean bags. Draw diagram as above.

Have children stand in two straight lines, with leaders on starting lines.

Give each child a bean bag, one side holding red and one side blue.

At a given signal the two leaders throw their bean bags, endeavoring to get them into the chalk circles; they then run to the rear of their lines, and second players throw their bean bags and also run to rear of lines. The game continues in this way until all bean bags have been played; the side having the greater number of bean bags in the circle wins.

Object.-Spirit of competitive play; attention. 


\section{HEARING AND CONCENTRATION}

Material.-Small clock.

For this exercise absolute quiet must be maintained in the schoolroom.

Teacher should blindfold a pupil; place the clock anywhere in the room, some distance from the child, then tell the child to go and find the clock. The child will listen for the ticking of the clock, and guided by the sense of hearing, go to the place where it is.

34.

\section{SENSE OF TOUCH}

If the day is warm and the children are out of doors, give them the following exercise to benefit their sense of touch.

Send children to gather a green leaf, a stone, a piece of twig, handful of earth, piece of bark, handful of grass, and anything else suitable that nature may provide.

Have the children sit quietly in a semi-circle. Place the different articles in a row; tie a handkerchief around one of the pupil's eyes.

Teacher should then ask him to pick out the stone; the child will feel with his fingers until he can locate desired object, which he will hold up for inspection of class.

Tell another child to pick out a different article.

Continue exercise in this way until each child has performed.

Object.-Sense of touch; memory; attention. 


\section{SINGLE LINE HOOP GAME}

\section{Material.-Hoop.}

Line up players in a single file; give each player a bean bag.

Have two players hold hoop in a horizontal position about four feet from ground. Make a chalk starting line ten feet from hoop on which leaders will stand.

At a given signal leader should throw his bean bag right through the hoop and run to the rear of the line; each player will throw in turn, the game continuing until all bean bags have been played and leader is once more on starting line.

Object.-Speed is not an object in this game, since there is no competition. It is to teach accuracy of aim; to develop play spirit; to train players for competitive games. 
36.

RELAY RACE

Place children in two lines of equal number, according to height. Leaders stand on starting lines.

Leader on one side will hold a red bean bag, and leader on the other side a blue bean bag.

At a given signal the leaders start off and run around chalk marks and back to starting line. As they pass second runner they give him the bean bag; on receiving same, he immediately runs as the leader did, and on his way to the rear of line hands the bean bag to the next boy.

The side having its leader back on starting line first wins the race.

Object.-Muscular control; attention.

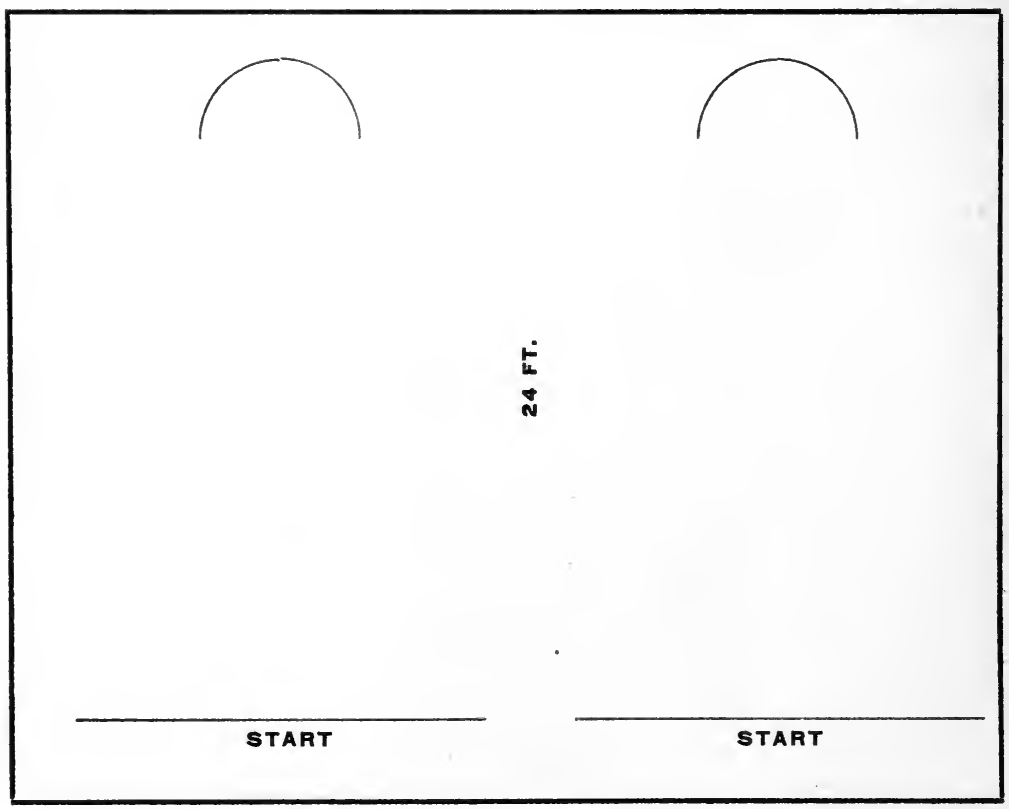




\section{SCHOOLROOM OBSERVATION}

The teacher should collect a number of articles, such as a piece of glass, wood, paper, iron, and anything else that may suit the occasion.

The teacher then takes the piece of glass, hands it to A, giving him also a pointer. Tell him to point out anything in the room that is made of glass, the same substance that he holds in his hand.

Call B and hand him the piece of wood; ask him to point out anything he can find in the room made of that substance.

Continue the exercise in this manner.

Object.-Stimulation of powers of observation.

\section{BIRD-FLYING EXERCISE}

Have children perfectly quiet.

Call upon A to imitate a bird, fly around the room and back to her seat.

A must run on tiptoes, with arms outstretched and waving slightly to imitate a bird's wings. She must go the whole way around the room and back to her seat, it all being done with the least possible noise.

For variation, the teacher may call upon three birds to fly together. They should follow one chosen for leader, and fly quietly around the room and back to their seats.

Have children repeat rhyme or song pertaining to birds during an interval in this exercise and they will more readily conceive the idea of imitating a bird.

Object.-Muscular control; attention; rest. 
39.

\section{ACTION SONG}

Tune: "The Night before the Fourth."

Have class sit in half-circle on kindergarten chairs, and interpret the different actions as they occur in the song.

I

We'll all stand up together,

We'll all stand up together,

We'll all stand up together,

As all good children do.

2

We'll all clap hands together.

3

We'll all keep step together.

4

We'll all march round together.

5

We'll all join hands together.

6

We'll all sit down together.

There is a good swing to the tune and action of this song which will stimulate the play spirit and sense of rhythm in the child: 
40. DAYS OF WEEK.-I.

Teach children to say the seven days of the week with the assistance of their hands, ticking off one finger for each day. Have them say each syllable very slowly and rhythmically, as Sun-day, Mon-day, Tues-day, Wednes-day, Thurs-day, Fri-day and Satur-day. This exercise must be practised slowly and deliberately to gain the desired effect, and children will be found to learn it in much the same way as a nursery rhyme.

\section{DAYS OF WEEK-II.}

After having taught children to memorize days of week with the assistance of their fingers, teacher should use the power of association of ideas to teach children to know the name of each day as it comes.

For example: Sunday is the day on which we go to Sunday School. Monday is the day on which mother does the washing; and so continue using the association of the unvarying routine of the child's life to impress upon the memory the name of each day in its correct order.

Object.-Memory; power of association of ideas. 


\section{DIRECTION AND ATTENTION}

Have children sit quiet in class.

Teacher may call upon A, tell him to walk to door and remain there until told to go to his seat. Call upon $B$ to walk to window and stay there. Call $\mathrm{C}$ to walk to table and remain.

As many as twelve children may be called upon to go in different directions; they must remain in position until told to go to their seats. Teacher should call upon each child separately, when sending them to their seats.

This exercise may be simplified by calling upon only three children to start, and gradually increasing the number.

Object.-To develop observation; sense of direction; attention; command.

\section{RUNNING EXERCISE}

After a sitting or quiet exercise children often show a tendency to become restless; in such cases, the following exercise will be found beneficial.

Commands to be given with precision, $e . g$. , children stand, feet togther, heads up, arms double. Then teacher says, "Are you ready? Run!"

Before this exercise can be successfully carried out, the child must be taught to recognize each command.

On the signal, "arms idouble," children clench fists tightly and double arms up so that the hands are in a straight line with elbow; keep elbows well in to the sides.

On the signal, "Run!" children remain in position and perform the exercise of running.

The shoulders must be kept well back, and the feet raised to the knees at each running step.

This exercise may be varied by allowing the children to run in a circle for about three minutes, and then quietly take their seats again.

Object.-Muscular control; discipline. 
44. CIRCLE HOOP GAME

Material.-Hoop, three and a half feet in diameter. Equal number of red and blue bean bags.

Players form a circle, four feet between each child.

Have two players hold the hoop about four feet from the ground in a horizontal position in the centre of circle.

Give each player a bean bag, alternating red and blue.

At a given signal one child should throw his bean bag, endeavoring to get it right through the hoop; each player will throw in turn until all bean bags have been played.

If the class is large, two score-keepers will be needed; one to keep count of red bean bags going through the hoop, and one to keep count of blue.

Should the red bean bags have the greater number thrown through the hoop, the players who hold that color win the game; the same principle applies to those holding blue.

Object.-To develop play spirit; accuracy of aim.

\section{COMMAND AND CONCENTRATION}

Material.-Red ball, yellow block, blue bean bag.

Place the above articles on a table and call upon child to perform.

The teacher should give commands in the following order, speaking slowly and distinctly.

Pick up bean bag and hold it.

Pick up block and hold it.

Put down bean bag and pick up ball.

Put down block.

Pick up bean bag and put down ball.

Pick up block.

Put down bean bag and block, and go to your seat. 
46.

FARMYARD GAME

Have class sit in semi-circle.

Teacher should call upon A to imitate a dog, e. g., go down on his hands and knees and run along the floor, imitating the bark of a dog; he will then return to his seat. Call upon B to imitate a cow; C to imitate a sheep; D to imitate a cat, and so forth, until the children have each an animal in mind to imitate.

If the class is large have several children imitate the same animal.

When the game has been played in this manner several times and the children have become familiar with the sounds the different animals make, the teacher should assign one corner of the room for a barn. At a given signal call upon all the animals to go to the barn, at which all the children will crawl rapidly along the floor to the barn, making the noise of the animal they are to imitate.

Object.-To stimulate play spirit; muscular control; observation.

\section{COLOR OBSERVATION}

Teacher calls upon a child to tell all the different articles of one color he can see in the room. Should the desired color be blue, the child should be told to look around the room and name every article that he can see of that color.

If the child has not learned to know color by name, the teacher should hand him a bright blue block or a bright blue ball and tell him to name all of like color that he can see in the room.

Should the child be unable to speak and yet have his color sense developed, the teacher should hand him a pointer and have him point out the different articles of desired color.

Object.-Develop powers of observation; color sense; attention. 
48.

\section{ROPE JUMPING}

A starting line fifteen feet from rope will be needed on both sides.

Place children in straight line, according to size, and have leader stand on starting line.

The rope must be held very steadily and raised not more than two inches each time the line renews jumping.

At a given signal the leader will run and jump; afterwards standing in position on starting line on opposite side of rope; the rest of the players will each run in turn and jump over rope, afterwards taking their places behind leader. Be sure one child has entirely cleared the rope before the next child starts to run, thereby avoiding confusion.

When all the players have jumped, rope will be raised and signal will be given again for leader to jump; exercise will continue as before.

This is a simple exercise, but if it is not carried out in a systematic, orderly manner the desired effect will be entirely lost.

Object.-Muscular control; develop play spirit; discipline. 


\section{FORM BUILDING}

Material.-Red blocks.

Teacher draws a chalk square on the floor, having sides three feet in length.

Give each child in class a block of same color, and have them come in turn and place their blocks on lines of square. Teach children to put their blocks equal distance apart to keep as far as possible the symmetry of the square. When form is finished, teacher should point to things in the room that are square, and ask children if the shape is not like that which they have just completed.

Next place a chalk circle on the floor of similar size, and have children in turn place their blocks on lines. When finished teacher holds up ball or anything in the room that may be round, and asks if each shape is not the same.

When children have become familiar with circle and square, other forms may be used in the same way. Do not use same color blocks on two consecutive forms.

The exercise may be varied by drawing forms of smaller size and putting them on the floor; have children make each form in different color. Example: Triangle in red blocks; square in blue blocks; oval in yellow blocks.

Object.-Color; form; attention. 
50. ODD MAN OUT

Material.-Eleven bean bags.

Place eleven bean bags in row on the floor about one foot space between each one.

Draw a starting line parallel with bean bags, eighteen feet distance between.

Call twelve children and have them stand on starting line. At given signal they should run, each child picking up bean bag and running back to starting line. The child not quick enough to get a bean bag is out.

The game is repeated, one bean bag being removed each time, until only one is left. The child getting the last bean bag wins the game.

This game may be played with any number of children, always having one less bean bag than players.

In playing this game out-of-doors, stones may be used instead of bean bags.

Object.-Develop play spirit; initiation.

51.

\section{ROUNDERS}

Material.-Medicine ball or bean bag.

Form a circle, children standing about four feet from each other. The ball or bean bag is thrown from one child to the next all around the circle. Those failing to catch it must sit in centre of circle until all but two players are standing; the last one up is the winner.

The above game may also be played with bean bags. Use two, and start them at the same time in different parts of the circle. This form of rounders calls for greater attention than medicine ball rounders.

Object.-Training the hand and eye; play spirit. 


\section{PLACES CHANGE-I.}

Have perfect quiet in the schoolroom during this exercise, that children may concentrate more readily.

Teacher must speak slowly and distinctly while giving commands. seat.

Call upon A to change places with B, and B to take A's

Continue this exercise, calling upon children in different parts of the class to change places with each other.

Do not continue this exercise for more than five minutes at one time.

\section{3.}

\section{PLACES CHANGE-II.}

When the children have gained in concentration and memory sufficiently to master the above exercise, the following more difficult exercise may be attempted.

Call upon $\mathrm{A}$ to change places with $\mathrm{B} ; \mathrm{B}$ to change places with $C$; and $C$ to go to the seat vacated by $A$.

When this exercise is first tried, the teacher should repeat command twice before allowing children to perform.

Object.-Memory; command; concentration. 


\section{$54 . \quad$ OBSERVATION}

Perfect quiet must be maintained in class during this exercise.

Teacher should call upon child and ask him to tell all the things he can see in the room.

Should the child's powers of observation be very weak, it is well to give him some help, for he will be unable to define what is really apparent to the eye.

Teacher should ask, for example: "What is that pretty thing I see on the wall ?" "What are the children sitting on?" "Where does teacher keep her book?" Such questions as these will open the child's mind and help him to think for himself.

Should a child be very backward in this exercise, do not try to force his attention; he will learn by observing others; send him to his seat, and call upon another child to perform.

Object.-Observation; concentration; command. 


\section{5.}

\section{BEAN BAG RACE}

Material.-Three blue bean bags, three red bean bags.

Mark floor plainly, according to diagram.

Place three red bean bags in one circle, and three blue bean bags in the other.

Choose two players; have them stand on starting lines. At a given signal they should run and place their bean bags on crosses marked for that purpose; only one bean bag may be carried at a time. The player having all bean bags placed on the crosses and back on the starting line first, wins.

This game may be varied by using blocks instead of bean bags. Using bean bags will call for less attention on the part of the players than blocks.

Object.-Muscular control; spirit of competitive play.

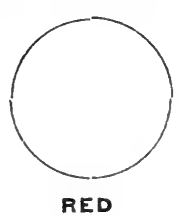

$\mathbf{x}$

$x$

$\mathbf{x}$
6 FT.

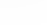

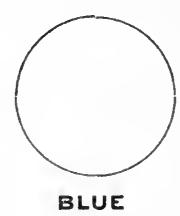

$\mathbf{x}$

$\stackrel{\circ}{\llcorner}$

$\stackrel{\infty}{-}$

$\mathbf{x}$

x 


\section{BLOCK STRUCTURE}

Material.-Equal number of red, blue, yellow, and green blocks.

Teacher should draw five chalk circles in front of class. In the middle circle teacher should build a structure of blocks. In the other four circles put one block of each color. The children should in turn place their blocks in circle of corresponding color; and as each child places his block he will help to form the different structures, imitating the one made by the teacher in the centre.

Object.-Color; attention.

\section{COMMAND AND CONCENTRATION}

Material.-Ball, spinning top, wooden block, bean bag.

Lay the above articles in a row on the table, call a child from class and give commands in the following order, speaking slowly and distinctly:

Pick up top.

Pick up ball.

Put down top and pick up bean bag.

Pick up block and top and put down the ball.

Put down block and top and pick up the ball.

Put down ball and pick up block, bean bag and top.

Put down block, bean bag and top, and go to your seat. 


\section{8.}

\section{CIRCLE THROW}

Material.-Equal number of red and blue bean bags.

Have children form a circle with three feet distance between each child. Make a chalk circle in the centre about four feet in diameter. Give each child a bean bag, alternating red and blue.

At given signal one child throws, endeavoring to get its bean bag into chalk circle. Each child follows in order.

When all the bean bags have been thrown, teacher should count those inside of chalk circle, separating the reds from blues. The color having the greater number in centre wins.

Object.-Accuracy of aim.

\section{CONCENTRATION AND MEMORY}

Material.-Bean bag, colored block, rubber ball.

Have children seated in half-circle.

Place a bean bag, a wooden block, and a rubber ball in front of children.

Call upon A to perform. Teacher should talk slowly and distinctly while giving commands.

Tell $\mathrm{A}$ to give bean bag to $\mathrm{B}$, block to $\mathrm{C}$, and give rubber ball to $\mathrm{D}$.

A should take the different articles and give them to the children whose names the teacher designates.

Should the child become confused and be unable to concentrate sufficiently to distribute three articles, use only two to start the exercise, until memory and attention is strengthened.

When child has become proficient with three, teacher should add one more, always taking care lest the exercise become too complex and create confusion in the mind of the child. 


\section{FORM BUILDING}

Material.-Blocks of one color.

Line up players in single file. Mark floor as per diagram. Give each child a block, all blocks being the same color.

Leader stands on starting line with rest of the players in line behind.

At a given signal the leader should run and place his block on one of the chalk crosses, after which he should run to the rear of line, and second player should follow in like manner. The exercise continues until all blocks have been placed and form is complete.

The form must consist of equal number of crosses as there are children playing.

Object.-Form; attention.

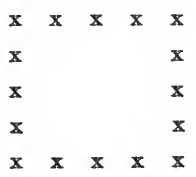




\section{DOUBLE LINE HOOP GAME}

Material.-Wooden hoop, three and a half feet.

Line up players in two straight lines, according to height.

Give each player a bean bag, one side holding red and other side blue.

Two of the larger players should hold hoop in a horizontal position in the middle of the two lines.

The lines should stand opposite each other, with a distance of twenty feet between the leaders.

Draw a chalk line on which each leader should stand, and from which each player in turn should throw his bag.

Leader on the red side plays first; object is to get his bean bag through the hoop; he then should run to rear of line, and leader on blue side should throw his bean bag in like manner; after which he also should run to rear of line, and second player should perform.

The game continues in this way until all bean bags have been played and leaders are once more on starting line.

Two score keepers will be needed; one to keep count of blue bean bags going through the hoop and one to keep count of red bean bags.

The side having the greater number of bean bags thrown through the hoop wins the game.

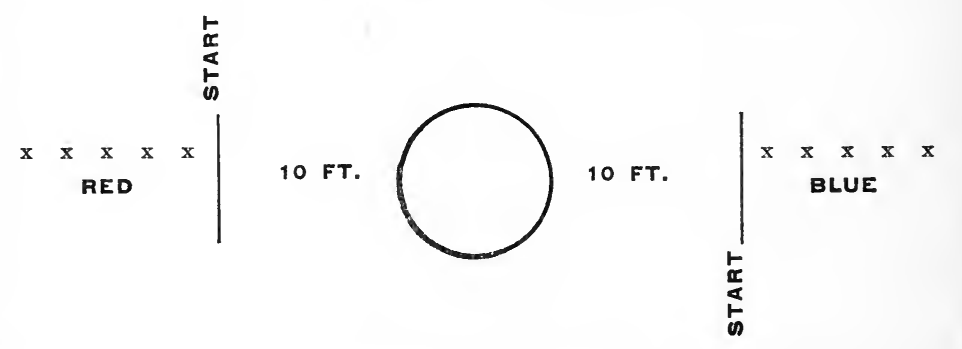




\section{HIDE THE BLOCK}

Call six children out of class and have them hide their eyes.

Teacher should take a bright colored block and hide it in a place where it will be found with little difficulty.

Hold up a block, an exact duplicate of hidden block, and tell the six children to go and find a block just like the one teacher is holding.

The children should scatter to different parts of the room and hunt for the block; the one finding it should bring it back to teacher.

Keep the duplicate block in view that the child may not forget the object for which he is searching.

Object.-Concentration; spirit of play; keenness of vision. 
63.

\section{ACTION SONG}

To be sung to the tune of "Here We Go Round the Mulberry Bush."

Children join hands in a circle and skip around while singing :

Here we go round the mulberry bush,

The mulberry bush;

The mulberry bush;

Here we go round the mulberry bush, So early in the morning.

(All stop skipping, and imitate cleaning teeth on following words.)

I

This is the way we clean our teeth

Clean our teeth;

Clean our teeth;

This is the way we clean our teeth

So early in the morning.

(Repeat verses, changing action each time.)

2

This is the way we brush our hair.

3

This is the way we wash our face.

4

This is the way we tie our shoes.

This is the way we clap our hands.

6

This is the way we run to school.

Object.-These words, coupled with action, will develop observation, sense of rhythm, and play spirit. 


\section{4.}

\section{OBSERVATION}

While out walking with children use the above exercise to develop power of observation.

Teacher should designate one child to tell all he can see around him.

Do not try to force his attention to observe details of the landscape until he has thoroughly awakened to those things that are apparent to the eye with little thought on the part of the observer.

The second child called upon will possibly imitate the first. Teacher should encourage children to find those things which others have overlooked.

Color sense may also be introduced in this exercise. The child may say, "I see a tree." Teacher may ask: "What color are the leaves?" The same question may be applied to the sky; a house; a field; etc.

\section{KEENNESS OF VISION}

Place a small table at one end of the room. On this table put six articles; for example, a cup, ball, hairbrush, spoon, book, and comb.

Have a child stand at the other end of the room, and name one by one the different articles on the table. The child must first be taught to know the name and use of any article placed thereon.

Some variation must be made in the articles each time the exercise is used; also the number may be increased. 


\section{BLOCK AND BASKET GAME}

Material._Eight blocks, four red and four blue; one basket.

Chalk floor plainly according to diagram.

Place four red blocks on crosses on one side, and four blue blocks on crosses on other side. back.

Choose two players to stand on starting lines, back to

At given signal players run and, picking up one block at a time, go back to centre and place it in the basket. The child having all blocks in the basket and back on the starting line first wins the game.

It is well to have each couple, after they have played, set out the blocks ready for the next players.

Object.-Concentration; muscular control.

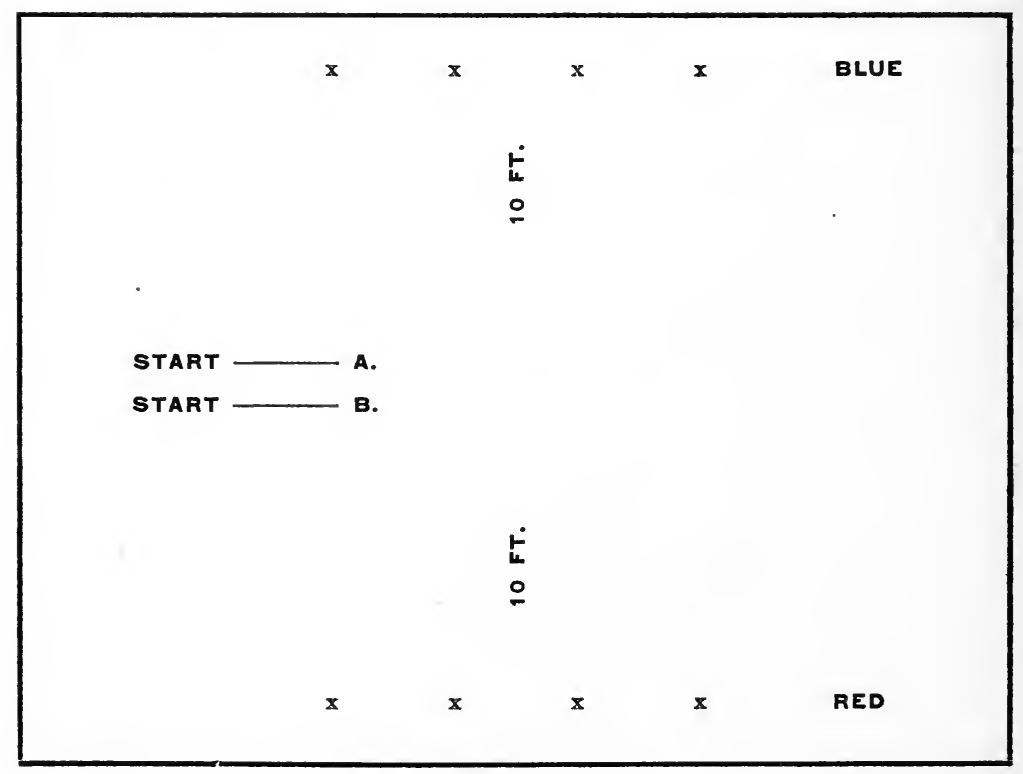


67.

\section{FORM MARCHING}

Line up children in single file, according to height.

Teacher should draw a chalk square on the floor twelve feet on each side. Have children take short, quick, marching steps, keeping directly on the lines of square.

When they have marched on the square twice, teacher should space them so that the last child and the leader are the same distance apart as the rest of the children. Then draw the children's attention to the fact they have formed a shape much like the picture or book, or anything in the room that may be square.

In the same way the teacher should draw a circle, oval, triangle, etc., and in this manner the child will become more familiar with form.

Object.-Muscular control; form; observation. 

PART III. 



\section{VISUALIZATION AND COLOR}

Material.-Four painted wooden blocks, one red, one yellow, one green, one blue.

Place blocks in a row on the table; call a child and ask him to look carefully at the blocks, noticing the color and the order in which they are laid; blindfold him and remove the blue block. Unbind his eyes and ask him which color block has been taken away.

Before this exercise is attempted, it is necessary that the child's color sense should be developed.

Object.-Memory; concentration.

\section{DROP THE BEAN BAG}

Form a circle, choosing one child for the odd player.

The circle players should clasp hands and stand still; the odd player should run around the outside of the circle, carrying a bean bag, and drop it behind the one whom she chooses to have chase her. The player behind whom the bag was dropped will immediately pick it up and run after the odd player, endeavoring to tag him before he can get back to the vacant place in the circle.

The player reaching the vacant place first remains there, the one left out taking the bean bag for the next game.

Note.-This is a variation of the game known as "Drop the Handkerchief," but it is much simplified for mental defectives when played in this way, because the noise which a bean bag makes when dropped on the floor will attract the child's wandering attention much more readily than the fall of a handkerchief.

Object.-Play spirit; attention. 
70.

\section{MARCHING}

Line up children in single file, according to size.

I. All stand in position and mark time.

2. March slowly with heads erect and arms straight down at sides.

3. Change from slow marching to quick marching.

4. Hands on hips and march.

5. All clap hands in time to march step.

6. Place one hand on each shoulder of the boy in front and march (elbows straight).

7. Hands on heads, elbows out, and march.

8. Heels raised, march on toes without noise.

9. Arms double*; all run.

Io. Form two lines and mark time.

II. Forward, march.

The above command, "Form two lines," is carried out by the second boy stepping forward and taking the leader's hand; the fourth boy taking the third boy's hand, and so on along the line. With practice it will be found this exercise can be carried out with much precision. The above commands must be given in a clear, decisive manner; the teacher should clap her hands in time to the marching, it will help develop sense of rhythm in the children; also count "one, two," "one, two." Do not use the terms left and right.

The command to stop should be "Halt! One! Two!" the word "halt" alone being too brief.

It is well to have children halt for a few seconds between each change in the marching.

Object.-Attention; coördination; muscular control.

*On the signal "Arms double," children clench fists tightly' and double arms so that the hands are in a straight line with elbows; keep elbows well in to the sides. 


\section{EXERCISE IN ROUGH AND SMOOTH SURFACES}

To teach the difference between rough and smooth surfaces take the following articles; six-inch square of sandpaper, six-inch square of smooth-finish paper. Call a child and give him the sandpaper; let him feel the rough surface without asking him questions, then give him the smooth-finish paper and have him feel that also.

Then take a six-inch square of glass and a six-inch square of emery, and repeat as with the paper. Do not ask questions.

This exercise may be repeated at different times until it is noticed the child is learning from his sense of touch that there is a difference between these articles.

Teacher should take the piece of sandpaper, hand it to the child, and tell him, while rubbing his fingers on the paper, that it is rough; next take the smooth-finish paper and again rub his fingers over the surface, and tell him it is smooth.

Continue this exercise, using different articles of smooth and rough finish, to develop this latent sense in the child.

When the child has learned to know smooth from rough, using senses of sight and touch, blindfold him and have him tell from sense of touch alone.

Object.-Concentration; memory; sense of feeling. 


\section{CENTRE BALL CATCH}

Material.-Medicine ball.

Children form a circle, three feet distance between each player, odd player in the centre holding ball.

On signal the game starts, centre player throws ball to one of the circle players who, catching it, throws it immediately back to centre player.

The ball is played in this order right around the circle, each child receiving the ball and throwing it back to centre player.

Should a player fail to catch the ball, he must sit on the floor in exactly the same place he is standing, and remain there until finish of game.

Should the centre player fail to catch, he must take his place in the circle, standing up and playing in turn with the rest, the one throwing to him having taken his place in the centre. Should he fail while taking his turn in the circle, he must then sit down with the others until finish of game.

It is well for the teacher or her assistant to act as centre catch, if the children are very slow to respond; a well-thrown ball will encourage the children to catch, and give more spirit to the game.

Object.-Sureness of aim; muscular control; concentration. 


\section{MEMORY AND COLOR}

Material.-Three blocks, red, blue, and yellow.

Children sit in semi-circle, on kindergarten chairs.

Place one red, one blue, and one yellow block before the class.

Call upon $\mathrm{A}$ to perform.

Tell A to give red block to B, blue block to $\mathrm{C}$, and yellow block to D.

Teacher should talk slowly and distinctly while giving this command, and have perfect quiet in the room that $\mathrm{A}$ may succeed in concentrating his mind more fully.

When the command is given A should take each block in turn and give it to the child designated by the teacher.

Object.-Concentration; memory; color.

\section{CIRCLE BLOCK BUILDING}

Material.-Equal number of red, blue, yellow, green, purple, and orange blocks.

Teacher should draw six circles upon the floor, placing a block of different color lengthwise in each one.

Children should sit in half-circle. Give each child a block.

Call upon first child to place his block in circle of corresponding color. The block must be placed crosswise on the block already there.

As each child plays, the structures of different colored blocks are made, each block being placed crosswise.

When the exercise is finished there are six structures of blocks, each of different color.

Should a child upset the structure while placing his block he must rebuild it before returning to his seat.

Object.-Concentration; muscular control; color sense. 


\section{BEAN BAG PASS}

Material.-Two bean bags, one red, one blue.

Line up players, according to height, in two straight lines facing each other, with a distance of ten feet between.

Leader of one line holds a red bean bag, and leader of the other line holds a blue bean bag.

At a given signal leader will pass his bean bag to next player; each player will pass the bean bag on until it reaches end player, who immediately runs to head of line; passing will continue, each end player running to the head of line as he receives bean bag.

The side having its leader back to head of line first wins the game.

Players must run back of lines, not inside.

This game may also be played with wooden blocks or medicine balls in place of bean bags.

NoTE.-Should this game be played out-of-doors, stones may take the place of bean bags.

Object.-Competitive play; muscular control. 


\section{HEARING GAME}

Material._Tambourine; clear-sounding bell.

Have class sit quietly in their seats; teacher should designate three children to take part in exercise.

Blindfold $\mathrm{A}$, give $\mathrm{B}$ a tambourine and $\mathrm{C}$ a clear-sounding bell. Have $\mathrm{B}$ and $\mathrm{C}$ go to opposite corners of the room and ring their instruments.

Teacher should lead A to center of room and tell him to find out who has the bell; A, guided by his sense of hearing, will go to $C$, who is ringing the bell.

Should a child be much confused by the sound of two instruments ringing at the same time, and seem totally unable to distinguish between the sounds, teacher should continue with Hearing Exercise I (see page I8) until sense of hearing is better developed.

Object.-Sense of hearing; concentration. 


\section{TRI-COLOR GAME}

Material.-Equal number of red, blue and yellow blocks.

Mark floor according to diagram; place one block in each circle of color called for.

Line up children in order, one behind the other, with leader on starting line.

Give each child one block; avoid giving two blocks of same color to children standing together.

At given signal A should run and place his block in circle having a like color.

After having placed block he should not return to the first line, but should go back to second line and thereby avoid distracting attention of $\mathrm{B}$, who is now running. When $B$ has placed his block, he should take his place immediately behind $A$, and other players will follow in order.

When game is finished, players will be lined up precisely the same as at start of game, except they will be standing on second line instead of first. If game is to be repeated players must go back to first line. No effort should be put forth by the teacher to gain speed in this game; its object is to develop color sense and attention.

Object.-Color sense; play spirit; concentration.

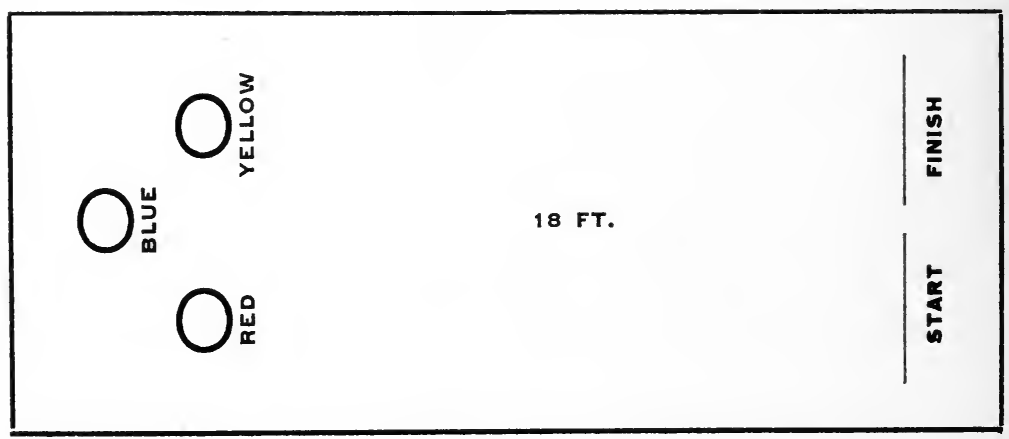




\section{SCISSORS WORK}

Material.-Small scissors and paper.

Give each child a pair of small scissors.

I. Teacher should cut paper into oblong pieces and give each child one piece.

Instruct children in way to hold scissors. Do not be particular as to way in which paper is cut; aim to have child hold scissors correctly in first cutting exercise. Colored paper is to be preferred in this exercise.

2. Teacher should take ten-inch squares of paper and draw parallel lines in colored pencil right across paper.

Have children cut directly on colored lines.

3. Teacher should take ten-inch squares of paper and draw curved parallel lines in colored pencil right across paper.

Have children cut directly on curved lines.

4. Teacher should make very simple geometrical forms on drawing paper. Let the paper be about ten by four inches in size; three forms would be sufficient on each piece of paper; for example, square, oval and triangle.

5. When a child has successfully passed the four preceding exercises in paper cutting, he will now be ready to take up very simple picture cutting. Be sure to choose pictures that are clear in outline and have very little detail.

Object.-Handwork; concentration. 
79.

\section{PAPER FOLDING}

Teacher should take eight-inch squares of firm paper and give one square to each child.

Have children stand around a table that all may be able to follow just what the teacher is doing.

Teacher should take one square of paper and fold it in half; have each child fold his square of paper in exactly the same way. Then teacher should fold the paper diagonally from one corner to the opposite corner, and have children do likewise with their paper.

Two folds will be quite sufficient to start this exercise. As children improve more folds may be attempted.

Object.-Handwork; concentration. 


\section{SINGLE LINE BLOCK BUILDING}

Material.-Equal number of red and blue blocks.

Mark floor as per diagram.

Line up children in one straight line; leader standing on starting line.

Give each child a block, alternating red and blue.

At a given signal the leader should run and place his block lengthwise on the cross; he should then run to rear of line, and second player should run and place his block crosswise on leader's block; likewise, he should go to rear of line, and third player should run. The exercise continues, each player placing his block crosswise on the one placed before, thereby building a structure of alternate red and blue blocks. Should a child upset the structure while placing his block, he must rebuild before taking his place at rear of line.

Object.-To develop muscular control and attention.

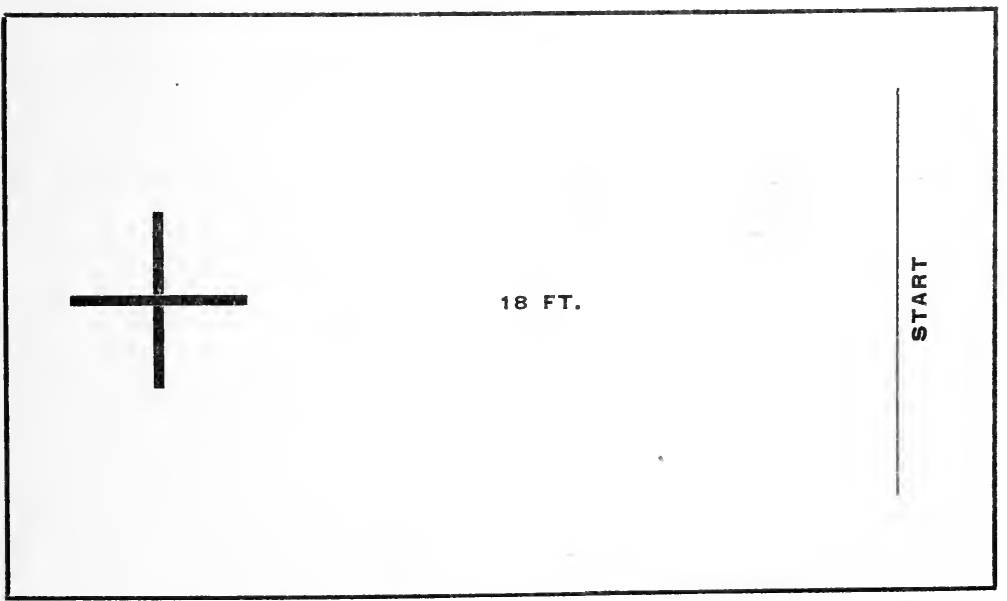




\section{COMMAND AND COLOR}

Material.-Four wooden blocks, one red, one blue, one green, and one yellow.

Place blocks in a row upon the table, call upon child to perform, and give commands in the following order.

Pick up red.

Pick up blue.

Put down red and pick up green.

Put down green and pick up yellow and red.

Put down blue, red and yellow and pick up green.

Put down green, and go to your seat.

Note.-Do not attempt this exercise until training has been given the child in color sense development. 


\section{2.}

\section{HOOP GAME}

Material.-Light wooden hoop, three and a half feet in diameter.

Place players in two straight lines according to height.

Give each player a bean bag, one line having red bean bags and one line blue.

Two of the larger players should hold hoop in a horizontal position in the centre of the two lines at a distance of seven feet from each leader, making a distance of fourteen feet between the two leaders.

Draw two chalk lines on which leaders of each side should stand.

At a given signal leaders on both sides should throw their bean bags, endeavoring to get them right through the hoop. After having played they should run to rear of line and second players will take their turn.

The game continues until all the bean bags have been thrown, and leaders are once more on starting line.

Two score keepers will be needed, one for blues and one for reds, to count how many bean bags go through the hoop.

The side having the greater number of bean bags go through the hoop, wins the game.

Object.-Accuracy of aim; competitive spirit. 
83. SIGHT EXERCISE

Material.-Articles of everyday use.

Teacher should place a number of articles on the table. Use only those articles the child is apt to come in contact with in everyday life, e. g., spoon, cup, brush, soap, ball, etc.

When the exercise is started use only six articles, and as the child progresses, slowly increase number.

Call a child from class; take a pointer and point out different articles on the table; have the child answer the names of articles as quickly as possible.

Should the child be unable to talk, teacher should call names of different articles and have child touch them with pointer as they are called.

Note.-This exercise must not be attempted until child has had training in the names and uses of the different articles.

Object.-Concentration; memory; sight.

84.

\section{CHAIR RACE}

Place six chairs in a straight line, if possible place them with their backs to the wall.

Make a starting line eighteen feet from chairs, and call upon seven children to stand on it.

At a given signal children should run and sit on a chair; the odd player not fortunate enough to get a chair is out.

Take one chair away and repeat game. The game continues until one chair is left, and two children to run.

The child successful in getting that chair wins the race.

Object.-Develop muscular control; attention; play spirit. 


\section{5.}

\section{COLOR STUDY}

Material.-A number of four-inch squares of bright colored pieces of cotton.

Mix the different pieces of cotton together and place them in a heap in front of the class.

Give each child one piece of colored cotton, taking care not to give the same color to children sitting next each other.

Teacher should call upon the first child to come and choose a piece of cotton, from the heap, to match the piece he has in his hand.

When he has the desired piece he should hold up the two pieces of cotton, one in each hand, for the inspection of the class. Teacher may ask the question, "Are John's colors right?" The class may answer "Yes" or "No," as the case may be.

Next child will perform in the same way, and the exercise will continue until all the children have matched their colors. 


\section{SIZE, COLOR, AND FORM}

Material.-Two boxes of marked difference in size, form and color. For example: One box twelve inches square and red in color; the other box round, about six inches in diameter and blue in color.

Put the two boxes side by side on the table, and call upon a child to perform.

Teacher holds up one box and asks the question, "What is this?" then holds up the other and asks the same question. "Are they both the same color?" "What color is this one?" indicating the red. "What color is this?" indicating the blue. "Are they both the same shape?" "What shape is this one ?" indicating the square. "What shape is this?" indicating the round. "Are they both the same size?" "Which is the larger?" "Which is the smaller?"

Teacher should ask the above questions slowly and distinctly, that the child may be better able to concentrate.

Object.-Concentration; form; size; color. 
87.

\section{STONE PICTURES}

Have the children each gather a small pile of stones. Let them be seated in a half-circle on the ground.

Teacher should take a pointed stick and draw a triangle in the soft earth in front of each child; the children will then take their stones and place them one at a time closely together on the lines, forming a triangle of stones. Children may then make a square, oval, circle, or any simple form the teacher thinks suitable.

Note.-If this game is played with children who are learning their letters and numbers, teacher should draw different numbers and letters, and let them fill in the lines with stones.

Object.-Handwork; attention.

\section{INDIAN FILE TARGET GAME}

To play this game it is necessary to have posts or trees upon which the target must be nailed.

A piece of board painted bright red, about twelve inches square, will be needed for the target; nail it securely to the post about four feet from the ground, or according to height of players.

Line up players in single file twelve feet from target; give them each a bean bag.

On signal, first player should throw his bean bag, endeavoring to hit target; after having played, he should then run to rear of line, and next player should take his turn. The game continues in this way until all players have thrown their bean bags, and leader is on starting line once more.

Object.-Accuracy of aim; attention. 


\section{COLOR PICK-UP}

Material.-Paper of different colors in bright shades; small boxes.

Teacher should cut paper into pieces of different sizes and shapes, and scatter them within a small space on the floor. Choose twelve children, and give each one a piece of paper and a small cardboard box. Have them pick up pieces of paper on the floor corresponding to the color of the piece which was given them. When all the pieces are picked up each child should show his box. The one having gathered the most pieces of correct color wins the game.

Note.-Do not attempt this exercise until training in color sense development has been given the child.

Object.-Handwork; application. 


\section{COMPETITIVE TRIPLE COLOR}

Material.-Red, blue, and yellow wooden blocks.

Chalk floor according to diagram. Place one colored block in each circle, block color matching circle color.

Place children in two lines, according to size; leaders of each line standing on starting lines. Give each child a block; take care that children standing next each other do not get blocks of the same color.

At a given signal leader of each line should run and place his block in circle having a like color; he should then run to back of his line, and second player will take his turn, also running to back of line when he has played. The game continues in this way until all blocks have been played, and leaders are once more on the starting lines.

Blocks must be placed in an upright position.

The side having its blocks in correct circles and its leader back on starting line first wins the game.

Note.-This game is only suitable for children whose color sense is developed, and for those who have had some training in competitive games.

Object.-Competitive spirit; attention.

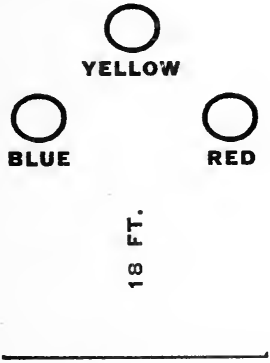

START

6 FT. 


\section{EXERCISE IN SIZE}

Material.-A number of marbles of one color and finish, but of four different sizes. Let the difference in size be marked.

Give each child about two dozen marbles and have him assort the different sizes, and put them into compartment boxes.

The above will be found to be an attractive as well as an instructive exercise, since most children take pleasure in handling marbles.

Object.-Attention; handwork; size.

\section{COMMAND AND COLOR}

Material.-Two blue blocks, two yellow blocks, one green, and one red.

Place blocks side by side on the table and call child to perform.

Give commands in the following order:

Pick up red and green.

Put down red and pick up two yellows.

Put down one yellow and pick up red and blue.

Put down red and pick up yellow and blue.

Put down two yellows and green and pick up red.

Put down two blues and one red, and go to your seat.

Note.-Do not attempt the exercise until color sense is well developed. 
93.

\section{BALL THROW}

Material.-Medicine ball, fourteen-foot rope.

Tie the rope five feet from the ground, or according to size of players, between two posts or trees, whichever may be available.

Divide players into two lines of equal number. Players line up on each side of the rope, facing each other, a distance of twelve feet between lines.

The game is started by the teacher, who throws ball to a player on one side, who in turn throws it over the rope to players on the other side. The game continues in this way, the ball being thrown from one side to the other. The ball must not be thrown to any particular player; it should be thrown from one group to the other, those catching it who can.

Should a player fail to catch the ball, it counts one point against his side. The first side having ten failures gives the opposite side the game.

Note.-This game is Volley Ball in simplified form.

Object.-To develop the spirit of competitive play; ball catching. 
94.

\section{ACTION CIRCLE GAME}

Children form a circle, hands on hips, feet placed together. Teach children following words, and as they repeat them have them carry out the action.

See my hands go clap, clap, clap.

See my feet go stamp, stamp, stamp,

Now my head nods one, two, three.

So skip merrily, merrily, we.

$\mathrm{Ha}$ ! $\mathrm{Ha} ! \mathrm{Ha}$ ! you and me.

So skip merrily, merrily, we.

On the words "Clap, clap, clap," children clap hands three times; on the words "Stamp, stamp, stamp," stamp the feet three times; on the words "One, two, three," nod the head three times; for the rest of the words children take hands and skip around until last "merrily we."

Object.-Sense of rhythm; play spirit; muscular control.

95.

\section{SENSE OF TOUCH}

Have children form a circle, having chosen two centre players to perform. Teacher should blindfold A; have $B$ come and stand within touching distance of $\mathrm{A}$.

Teacher should put the question to A, "Who is it?" and by feeling clothing, face, hair, and so forth, A will tell the name of $B$.

When $\mathrm{A}$ has told the name of $\mathrm{B}$, choose two other children to perform.

Object.-Concentration; sense of touch. 
96.

\section{CIRCLE TOSS}

Cut five cardboard circles. Make each circle bright red on one side and bright blue on reverse.

Children may choose whichever color they prefer. Those choosing red stand on one side; those choosing blue on the other.

Teacher should throw cardboard circles into the air one at a time. The majority of those falling to the ground with blue side up cause the blues to win; the majority falling with red side up cause reds to win.

Throwing the circles into the air one at a time holds the children's interest more readily, and is less likely to cause confusion in their minds than throwing all together.

Object.-Color sense; play spirit. 


\section{BEAN BAG RELAY}

Material.-Bean bags; shallow box.

Place players, according to size, in two lines of equal number.

Mark floor according to diagram.

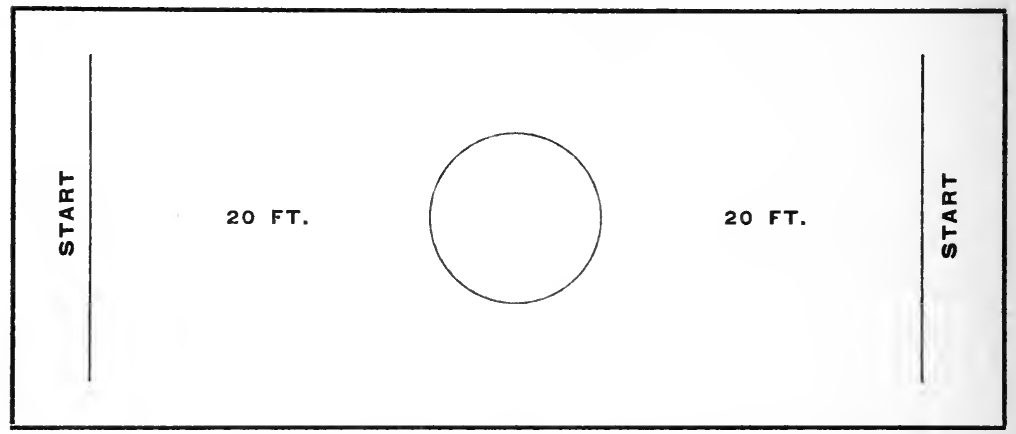

If a shallow box or basket cannot be procured, a chalk circle will answer the purpose.

Lines in position, with leaders on starting lines.

Give each player a bean bag, those on one side having red bean bags, those on the other side blue.

At a given signal the leader of each side should run and drop his bean bag into the basket (it must not be thrown into the basket), he should then take his place at end of line, and as he runs over starting line second player should run.

Each player should run in turn until leaders are once more on starting lines. The side having played off all their bean bags, and having their leader back to starting line first, wins the game.

Should this game be played out-of-doors, stones may take the place of bean bags.

Object.-Competitive spirit. 
98.

\section{TARGET GAME}

Material.-Two pieces of board twelve inches square, painted bright red, for targets; nail them securely six feet from ground to a tree or post, with ten feet between.

Make two starting lines opposite targets, at twelve feet distance.

Place players in two lines of equal numbers, leaders standing on starting line. Give each player a bean bag, red bags for one side, and blue for the other side.

Two score-keepers will be needed, one for blues and one for reds, to count how many bean bags hit the target.

At a given signal the leaders on both sides should throw their bean bags, endeavoring to hit target. After having thrown they should each run to the rear of their line, and game will be repeated, each player throwing his bean bag at the target and then running to the end of the line. The side having the greater number of bean bags hit the target wins the game.

Object.-Accuracy of aim; to develop spirit of competitive play. 
99.

\section{COLOR THROW}

Material-Six bean bags, green, yellow, red, blue, orange and purple.

Children sit in semi-circle on small chairs.

Teacher should throw one bag each to children in different parts of class.

Call upon Red to throw his bean bag to teacher; call upon Yellow to throw his bag; call upon Green, and so continue until all bean bags have been returned in their right order.

Choose six other children and continue exercise.

Object.-Sense of color; attention.

100.

\section{PICK UP STICKS}

This game is suitable only in woods or groves where there may be small, dry sticks to gather.

Have children search for all the sticks they can find; small, dry twigs of any kind will answer the purpose.

When twigs are gathered, children should sit on the ground in a semi-circle, each child having a dozen or more sticks to work with.

Teacher should sit in front of class and using sticks somewhat larger than the children have, make a simple pattern for them to copy.

Teacher should make the pattern slowly and let children work with her. As one stick is laid by the teacher, one stick can be laid by the children. Let the patterns be very simple to start with, square, triangle, oblong, alphabetic letters such as $\mathrm{A}, \mathrm{T}, \mathrm{E}, \mathrm{V}, \mathrm{H}$, etc.

When children have learned to put their sticks together so that they can follow a simple pattern, more difficult patterns may be used.

Object.-Concentration; handwork; observation. 


\section{FORM STUDY IN BLACK AND WHITE}

Material.-Number of geometrical forms, square, circle, oval, triangle, etc., one side black and reverse side white, made of very thin wood, size about six inches; one large form eighteen inches in size will be needed for every six small forms.

Children should be seated on low chairs in semi-circle.

Teacher should place large geometrical forms on the floor, in a straight line, with the white side up. Give each child a small form. First child will come out of class and place his small form on large form of corresponding shape, white side up. He will then take his seat, and next child will perform. The exercise continues in this way until each child has placed his form.

When this exercise is next used the large form may be placed on the floor with black side up, and children place their forms accordingly.

This exercise may also be varied by placing the large forms on the floor, alternating black and white, thereby making the exercise more difficult and taxing the child's powers of concentration more keenly.

Object.-Form; concentration. 
102.

\section{BLOCK STANDING}

Material.-Equal number of red and blue blocks.

Teacher should chalk floor as per diagram. Place players, according to size, in two lines of equal number.

Have leaders stand on starting lines; give each child a block, red for one line, and blue for the other.

At a given signal children should run in relay style and place their blocks on end in the circle. If the block should drop lengthwise they must stop and place it on end. Should a player knock another block down while placing his, he must replace it upright before returning to his line.

The line having all their blocks placed in circle, and their leader back on the starting line first, wins the game.

Object.-Spirit of competitive play.
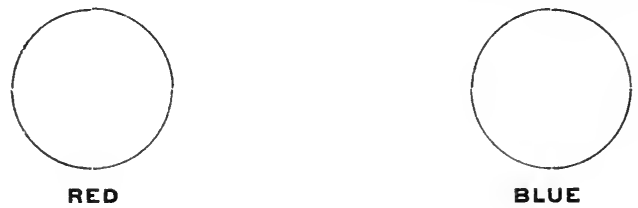

START 


\section{COLOR CIRCLE THROW}

Material.-Red, blue, and yellow bean bags.

Form a circle, children standing considerable distance apart. Draw three circles as per diagram; put one bean bag in each circle of like color.

Give each child a bean bag, alternating red, blue and yellow. At a given signal the game should start, each player throwing his bean bag in turn and endeavoring to get it into the circle of corresponding color. When all bean bags have been played, teacher should count the bags in the circle having the greatest number correctly thrown. The players who have thrown the greatest number of bags of same color as circle, win the game.

Object.-Color; accuracy of aim.

$$
\text { X } \quad \text { X }
$$

$\mathbf{x}$

$\mathbf{x}$

$\mathbf{x}$

X

X

$\mathbf{x}$

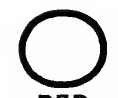

$\mathbf{x}$

$\mathbf{x}$

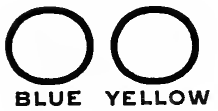

$\mathbf{x}$

$\mathbf{x}$

X

$\mathbf{x}$

$\mathrm{x}$

X $\quad$ X 


\section{EXERCISE IN LENGTH}

Material.-Sticks of wood painted bright red, in four, three, two and one inch lengths.

Mix the different lengths together. Have children stand around the table. Give each child a handful of sticks and have him assort the different lengths.

As he matches the different lengths he should put them neatly side by side.

If this exercise proves confusing to the child, and he is not able to assort the four different lengths, the teacher should take away the three and one inch lengths, and have him assort only the four and two inch lengths. In this manner the exercise will be much simplified.

\section{MEDICINE BALL LINE-UP}

Material.-Medicine ball.

Players should be in two lines facing each other, eight feet between lines.

Give the ball to the leader on line $A$ and have him throw it to leader on line B; after having thrown the ball, leader on line A should immediately run to the end of his line. After having received the ball, leader on line $B$ should throw it back to second player on line $\mathrm{A}$, and leader on line $B$ should run to the end of his line. The game continues in this way, each player throwing the ball to the opposite player and then running to the end of his line.

Scores must be kept on both sides to keep count of the number of failures in catching.

The side having the least number of failures wins the game.

Object.-Concentration; competitive spirit; train eye and hand for ball catching. 


\section{BLOCK BUILDING RELAY}

Material.-Equal number of red and blue wooden blocks.

Draw diagram as below.

Children stand in two lines with leaders on starting lines. Give each child a block, one line having red, and one line blue.

At a given signal, the leaders of each line should run and place their blocks lengthwise on the chalk crosses. The leaders should then each run to the rear of their lines, and the two second players should run and place their blocks crosswise on the first players' blocks; they should then run to the rear of their lines, and third players should run; the game continuing in this way until all the blocks are played, and two structures of crosswise blocks are made, one of blue and one of red. Should a player upset the structure while placing his block, he must rebuild it again before running to the rear of line.

The side having its structure made, and its leader back on starting line first, wins.

Object.-Muscular control; concentration.
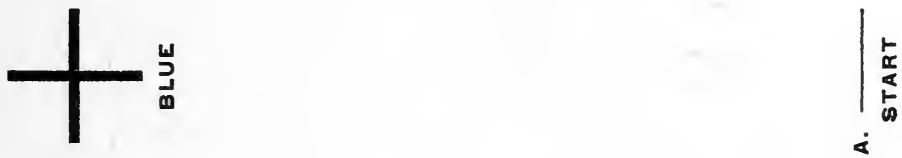

20 FT.
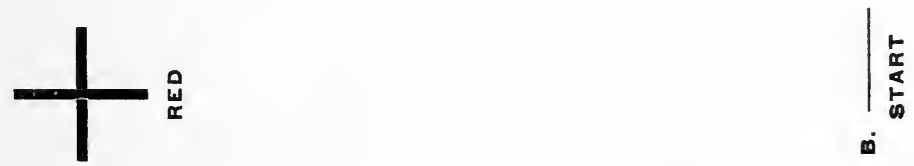


\section{COMMAND, COLOR, AND CON- CENTRATION}

Material.-Eight wooden blocks, two blue, two red, two yellow, two green.

Call child from class and give following commands slowly and distinctly:

Pick up one red block, one green and one blue.

Put down one red and pick up two yellow blocks.

Put down one yellow and pick up two red blocks.

Put down one red, one yellow and one green and pick up one blue.

Put down one red and one blue and pick up two greens and one yellow.

Put down two greens, one yellow, and one blue, and go to your seat.

Absolute quiet must be maintained in the schoolroom during this exercise.

Note.-Color sense training must be given the child before any attempt be made at this exercise. 
108.

\section{FORM BUILDING}

Material.-Twenty-four wooden blocks, twelve red and twelve blue.

Mark floor according to diagram.

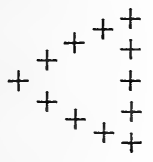

$18 \mathrm{FT}$.
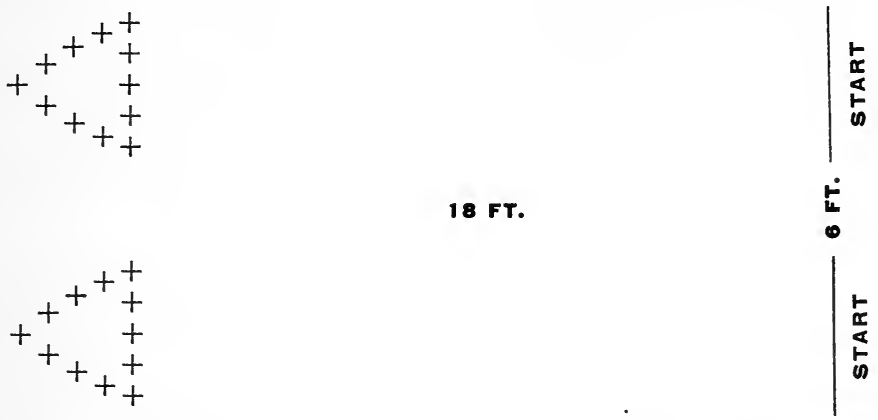

Line up children, according to size, in two lines of twelve. Give children each a wooden block, one line having red and one line blue.

Leaders stand on starting lines.

At a given signal leaders should run and place their blocks on end on one of the little crosses in the triangle. They should then run to the end of line and second players should run and place their blocks in like manner. The game continues until all the blocks have been placed, and leaders are once more on starting lines.

The blocks must be placed upright. Should a player knock another block down while placing his, he must replace it before running back to his line. The side having all of its blocks placed and its leader back on starting line first, wins the game.

The diagram may be varied by drawing any simple geometric forms such as square, oval, circle, etc.

Object.-Form; spirit of competitive play. 
109.

\section{FEELING}

Material.-One tennis ball, golf ball, baseball, small gas ball, woolen ball, glass ball, wooden ball.

Preparatory to this exercise the child must be taught by sense of sight to know these different balls, and to call them by name.

Place the balls on the table and call upon a child to perform; blindfold his eyes and hand him one ball at a time and have him tell the class the name of the ball he is holding.

Should the child be unable to speak, teacher should say, "Give me the tennis ball!" The child should feel among the balls and hand teacher the tennis ball.

Continue exercise in this way.

Object.-Concentration; sense of touch; memory.

\section{BALL BOUNCING-I.}

Material.-Rubber balls.

Make a straight chalk line and have children stand side by side on it.

Give each child a rubber ball.

Children must play in turn. Have child throw ball into the air and catch it as it returns. The ball may be thrown about two feet. Let this exercise be repeated many times.

Children must play one at a time or confusion will ensue. 
111.

\section{BALL BOUNCING-II.}

Children should stand in position on chalk line. Give each child a rubber ball.

Teacher should call upon the first child to bounce ball once. When the first child has bounced his ball, call upon the second.child, and so continue along the line. Should a child fail to catch the ball, do not stop to have the child repeat, but continue to end of line, and then repeat the exercise right through.

\section{BALL BOUNCING-III.}

Teacher should collect balls and have children stand in half-circle.

Bounce one ball each to the children, giving each their ball in turn and bouncing them diagonally. When all balls have been played children should then bounce them back to teacher, first child leading, and each child playing in turn.

Note.-Four minutes' free play with the balls may be allowed after each of these ball-bouncing exercises.

Object.-Train eye and hand for ball catching; attention. 


\section{COLOR AND FORM PUZZLES}

\section{I}

For these exercises use twelve-inch forms made of thin wood, painted in bright colors.

For beginners, take the colors blue, red, and yellow, and use only circles and squares. Each form should be cut into two pieces.

Give each child four pieces; for example, two pieces of red comprising one red circle, and two pieces of blue comprising one blue square.

The next child could have two yellow pieces forming a yellow circle, and two red pieces forming a red square.
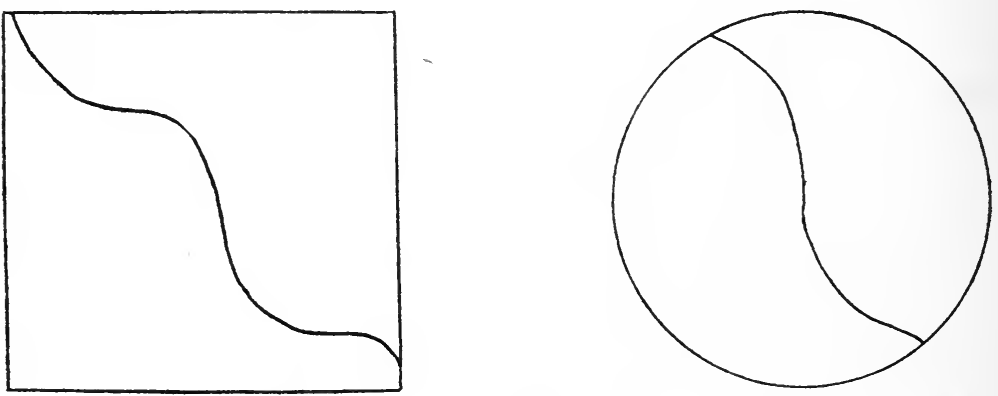


\section{COLOR AND FORM PUZZLES}

\section{II}

For a more advanced class, use blue, red, yellow, and green colors, and square, circle, oval, and diamond forms. Each form must be cut into three pieces. Give each child six pieces, with which he should make two complete forms; for example, three yellow pieces forming an oval, and three green pieces forming a diamond.
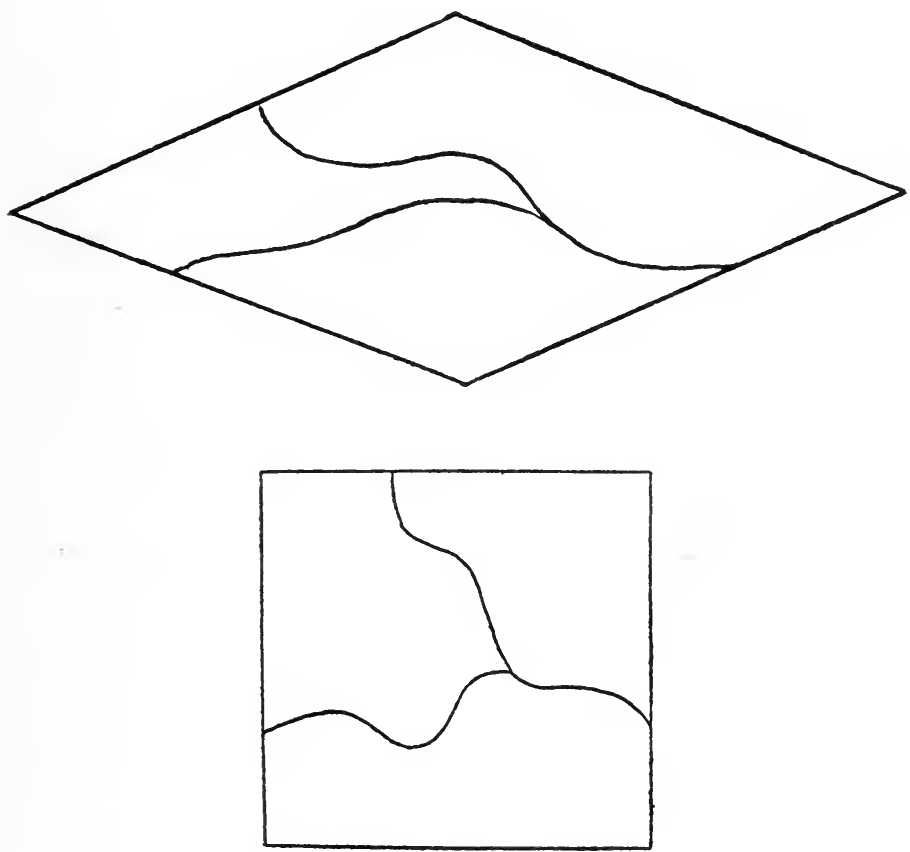
94

GAMES AND EXERCISES

115. COLOR AND FORM PUZZLES

III

For more advanced class use colors red, blue, yellow, green, purple, and orange. Use as forms ovals, squares, diamonds, oblongs, circles, and triangles; each form must be cut into five pieces.

One child may have three forms, or fifteen pieces, representing three forms of different color when put together.

Color sense development is necessary before this last exercise may be attempted.
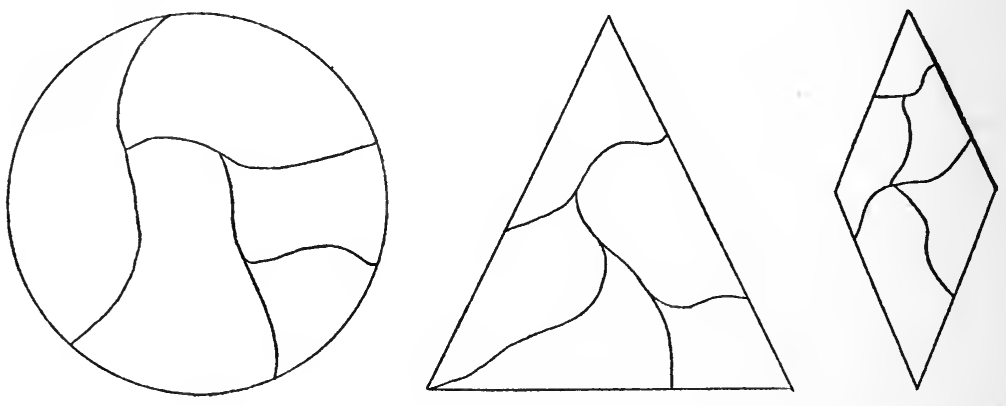


\section{LIST OF EXERCISES AND GAMES}

\section{PART I}

Introduction

Exercise

1. Bean Bag Catch...................... 11

2. Roll Ball ......................... 11

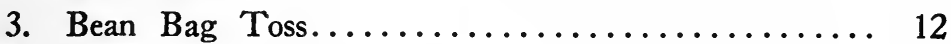

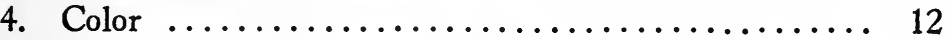

5. Command and Concentration ............... 13

6. Bowling ......................... 13

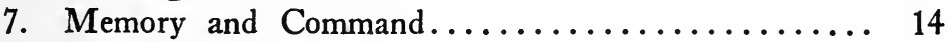

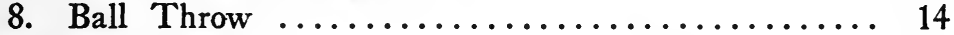

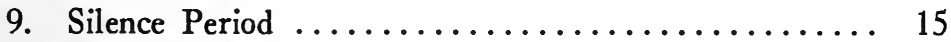

10. Block Placing ...................... 15

11. Color Exercise ..................... 16

12. Rolling Rounders .................... 16

13. Muscular Control ..................... 17

14. Shoe Lacing Exercise.................... 17

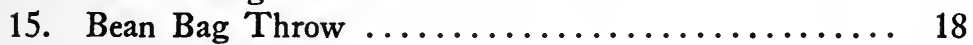

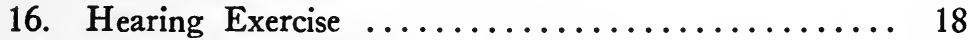

17. Medicine Ball Throw .................... 19

18. Tiptoe Exercise .................... 19

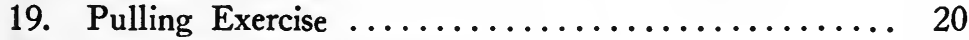

20. Command and Concentration .............. 20

21. Bell Circle ........................ 21

22. Sit and Stand ...................... 21

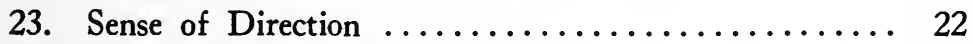

24. Hoop Game ...................... 22

25. Direction and Command $\ldots \ldots \ldots \ldots \ldots \ldots \ldots \ldots, 25$

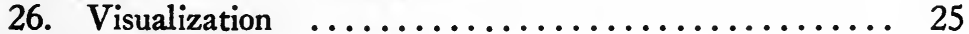


EXERCISE

27. Single Line Block Standing ............... 26

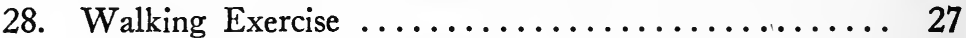

29. Command and Observation $\ldots \ldots \ldots \ldots \ldots \ldots \ldots, 27$

30. Broad Jump ..................... 28

31. Muscular Control $\ldots \ldots \ldots \ldots \ldots \ldots \ldots \ldots \ldots \ldots . \ldots \ldots$

32. Bean Bag Throw ..................... 29

33. Hearing and Concentration $\ldots \ldots \ldots \ldots \ldots \ldots \ldots \ldots$

34. Sense of Touch ..................... 30

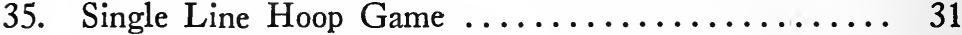

36. Relay Race ...................... 32

37. Schoolroom Observation $\ldots \ldots \ldots \ldots \ldots \ldots \ldots \ldots . \ldots \ldots$

38. Bird Flying Exercise .................. 33

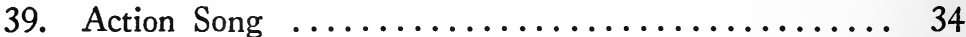

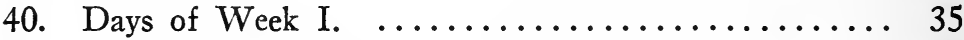

41. Days of Week II. .................. 35

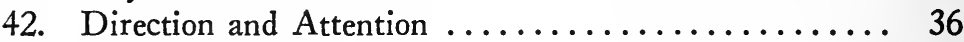

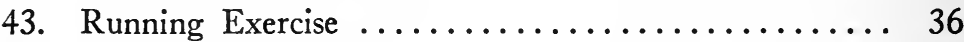

44. Circle Hoop Game.................... 37

45. Command and Concentration ............. 37

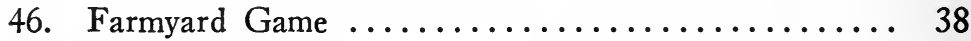

47. Color Observation $\ldots \ldots \ldots \ldots \ldots \ldots \ldots \ldots \ldots . \ldots . \ldots$

48. Rope Jumping ................... 39

49. Form Building .................... 40

50. Odd Man Out ...................... 41

51. Rounders ..................... 41

52. Places Change I. ................... 42

53. Places Change II. .................... 42

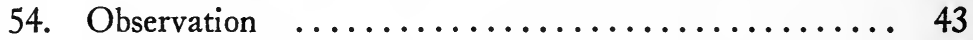

55. Bean Bag Race ..................... 44

56. Block Structure .................... 45

57. Command and Concentration ............. 45

58. Circle Throw ....................... 46

59. Concentration and Memory .............. 46

60. Form Building ................... 47

61. Double Line Hoop Game ................ 48

62. Hide the Block .................... 49

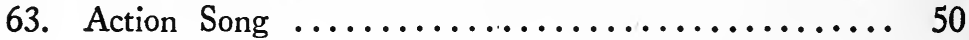


EXERCISE PAGE

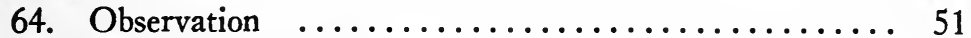

65. Keenness of Vision ................... 51

66. Block and Basket Game ................ 52

67. Form Marching .................. 53

\section{P A R T I I I}

68. Visualization and Color ................ 57

69. Drop the Bean Bag $\ldots \ldots \ldots \ldots \ldots \ldots \ldots \ldots \ldots \ldots$

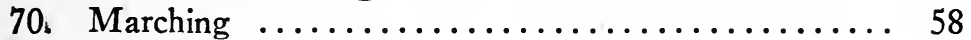

1. Mark Time.

2. Slow Marching.

3. Quick Marching.

4. Hands on Hips and March.

5. Clap and March.

6. Hands on Shoulders and March.

7. Hands on Heads and March.

8. Silent Marching.

9. Arms Double, Run.

10. Double Lines; Mark Time.

11. Forward, March.

71. Exercise in Rough and Smooth Surfaces ......... 59

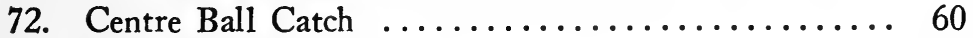

73. Memory and Color ................... 61

74. Circle Block Building ................. 61

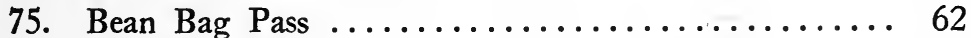

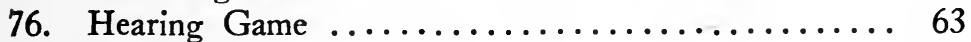

77. Tri-color Game ................... 64

78. Scissors Work ..................... 65

1. Paper Cutting.

2. " " on straight lines.

3. " " on curved lines.

4. Cutting out Forms.

5. Cutting Simple Pictures.

79. Paper Folding ..................... 66

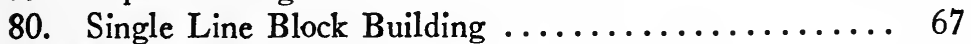

81. Command and Color .................. 68

82. Hoop Game $\ldots \ldots \ldots \ldots \ldots \ldots \ldots \ldots \ldots \ldots . \ldots 6$ 
83. Sight Exercise .................... 70

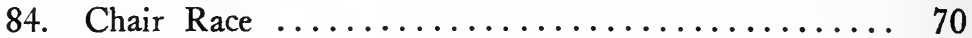

85. Color Study ..................... 71

86. Size, Color and Form ................ 72

87. Stone Pictures .................... 73

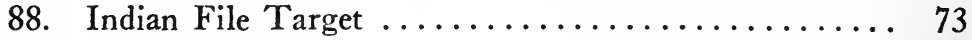

89. Color Pick-up .................... 74

90. Competitive Triple Color .............. 75

91. Exercise in Size .................... 76

92. Command and Color ................. 76

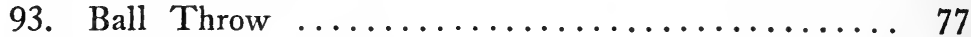

94. Action Circle Game ................... 78

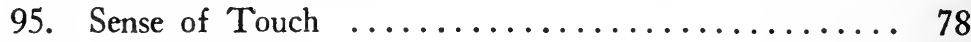

96. Circle Toss ....................... 79

97. Bean Bag Relay .................... 80

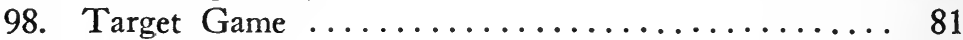

99. Color Throw .................... 82

100. Pick up Sticks .................... 82

101. Form Study in Black and White ............ 83

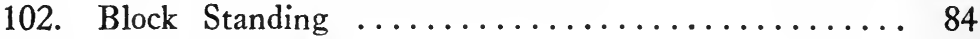

103. Color Circle Throw ..................... 85

104. Exercise in Length .................. 86

105. Medicine Ball Line Up................ 86

106. Block Building Relay ................... 87

107. Command, Color, and Concentration........... 88

108. Form Building .................... 89

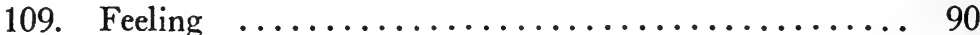

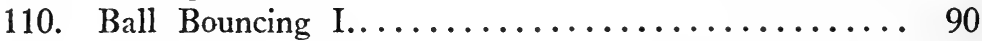

111. " " II. $\ldots \ldots \ldots \ldots \ldots \ldots \ldots \ldots \ldots \ldots \ldots . \ldots 1$

112. " " III. .................. 91

113. Color and Form Puzzles I............... 92

114. " " " "

115. " " " 


\section{INDEX}

Action Circle Game, 78

Action Song, 34, 50

Ball Bouncing, 90, 91

Ball Throw, 14, 77

Bean Bag Catch, 11

Bean Bag Pass, 62

Bean Bag Race, 44

Bean Bag Relay, 80

Bean Bag Throw, 18, 29

Bean Bag Toss, 12

Bell Circle, 21

Bird-flying Exercise, 33

Block and Basket Game, 52

Block Building Relay, 87

Block Building, Single Line, 67

Block Placing, 15

Block Standing, 84

Block Standing, Single Line, 26

Block Structure, 45

Bowling, 13

Broad Jump, 28

Center Ball Catch, 60

Chair Race, 70

Circle Block Building, 61

Circle Hoop Game, 37

Circle Throw, 46

Circle Toss, 79

Color, 12

Color and Form Puzzles, 92, 93, 94

Color Circle Throw, 85

Color Exercise, 16

Color Pick-up, 74

Color Observation, 38

Color Study, 71

Color Throw, 82

Command and Color, 68, 76

Command and Concentration, 13, $20,37,45$

Command and Observation, 27

Command, Color and Concentration, 88

Competitive Triple Color, 75

Concentration and Memory, 46
Days of Week, I, II, 35

Direction and Attention, 36

Direction and Command, 25

Drop the Bean Bag, 57

Farmyard Game, 38

Feeling, 90

Form Building, 40, 47, 89

Form Marching, 53

Form Study in Black and White, 83

Hearing and Concentration, 30

Hearing Exercise, 18

Hearing Game, 63

Hide the Block, 49

Hoop Game, 22, 69

Hoop Game, Double Line, 48

Hoop Game, Single Line, 31

Introduction, 5

Indian File Target Game, 73

Jump, Broad, 28

Jumping Rope, 39

Keenness of Vision, 51

Length Exercise, 86

Marching, 58

Medicine Ball Line-1p, 86

Medicine Ball Throw, 19

Memory and Color, 61

Memory and Command, 14

Muscular Control, 17, 28

Observation, 43, 51

Odd Man Out, 41

Paper Folding, 66

Pick Up Sticks, 82

Places Change, I, II, 42

Pulling Exercise, 20

Relay, Block Building, 87

Relay Race, 32

Roll Ball, 11 
Rolling Rounders, 16

Rope Jumping, 39

Rough and Smooth Surfaces, Exercise, 59

Rounders, 41

Running Exercise, 36

Schoolroom Observation, 33

Scissors Work, 65

Sense of Direction, 22

Sense of Touch, 30, 78

Shoe-I acing Exercise, 17

Sight Exercise, 70

Silence Period, 15

Sit and Stand, 21

Size, Color and Form, 72
Size Exercise, 76

Stone Pictures, 73

Surfaces, Rough and Smooth, Exercise, 59

Target Game, 81

Target Game, Indian File, 73

Tiptoe Exercise, 19

Tri-Color Game, 64

Triple Color, Competitive, 75

Vision, Keenness of, 51

Visualization, 25

Visualization and Color, 57

Walking Exercise, 27 



\section{UNIVERSITY OF CALIFORNIA LIBRARY BERKELEY}

Return to desk from which borrowed.

This book is DUE on the last date stamped below.

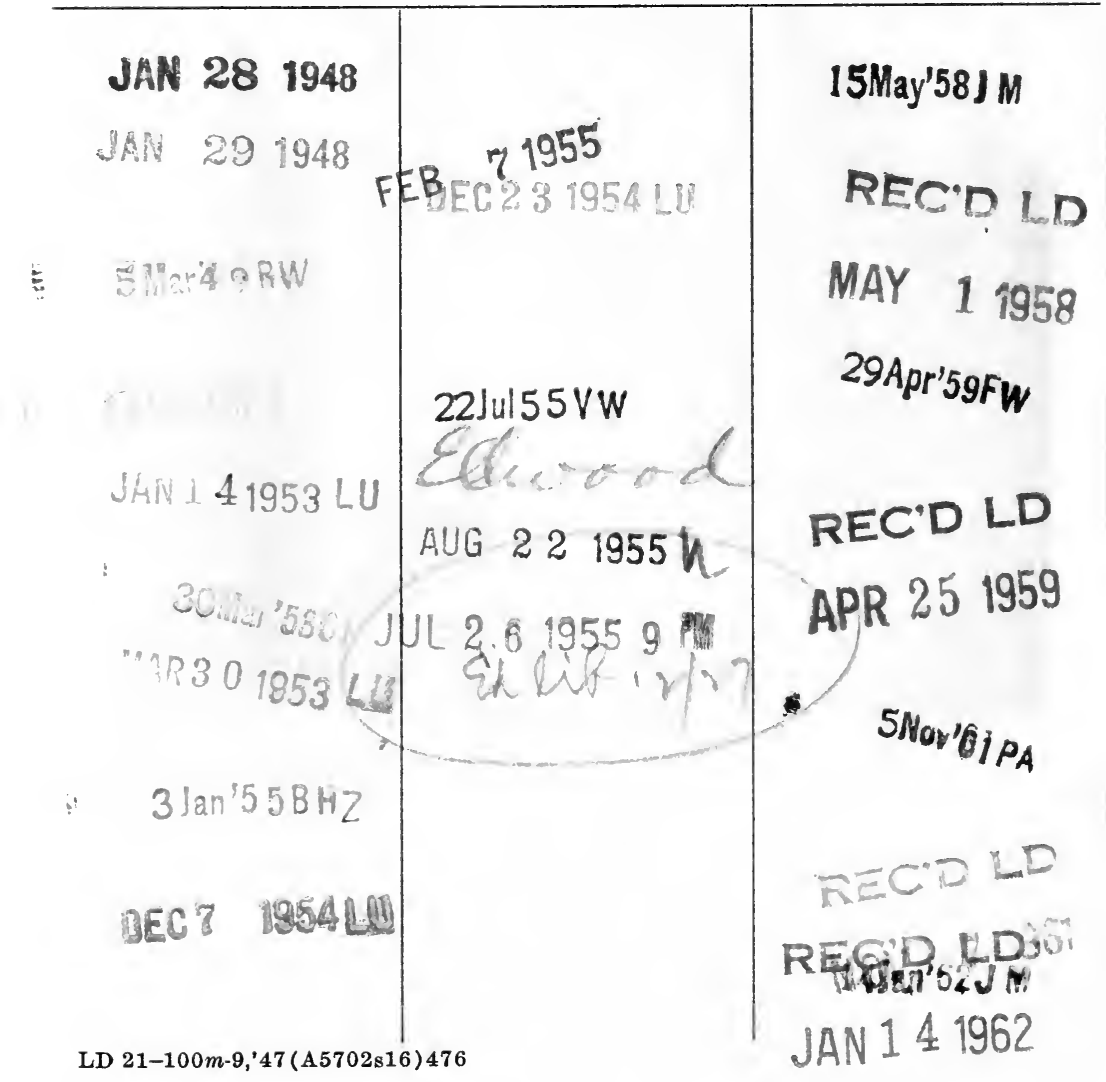


